\title{
Optimal taxes and penalties when the government cannot commit to its audit policy*
}

\author{
Leandro Arozamena ${ }^{\dagger} \quad$ Martin Besfamille Pablo Sanguinetti $^{\ddagger}$
}

October 25, 2010

\begin{abstract}
We examine the problem of a utilitarian government that sets taxes and fines for evaders but cannot commit to any enforcement policy. Given the tax law, the government and taxpayers -some of whom are honest- play a report-audit game that, depending on taxes, fines and audit costs, generates either full evasion and no audits, or partial evasion and random auditing. Anticipating both possibilities, we characterize the optimal tax law. We show that it may be optimal for the government not to fine evaders as a way to commit not to audit. Moreover, social welfare is nonmonotonic in the audit cost.

Keywords: Tax rates - Tax evasion - Enforcement - Audit costs - No commitment - Mixed-strategy equilibrium.

JEL Codes: D82 - H26.
\end{abstract}

${ }^{*}$ We thank the editor, J. Conley, an associate editor, and two anonymous referees for their helpful comments and suggestions. We also thank J. Anderson, G. Casamatta, H. Cremer, P. De Donder, J. Dubra, J. Eeckhout, E. Espino, C. Marchese, P. Pestieau, M. Raybaudi-Massilia, M. Solá, L. Toolsema, C. Traxler, participants at the 9th International Meeting of the Association for Public Economic Theory (Seoul, 2008), the 64th Congress of the International Institute of Public Finance (Maastricht, 2008), IX Jornadas Latinoamericanas de Teoría Económica (San Luis, 2008) and seminar participants at Université de Toulouse, CEA - Universidad de Chile and Universidad Torcuato Di Tella for very useful comments. We also thank A. Bellofatto and G. Navarro for their research assistance. All remaining errors are our sole responsibility. Part of this paper has been written when M. Besfamille visited GREMAQ and IDEI (Université de Toulouse), whose hospitality is gratefully acknowledged. M. Besfamille and P. Sanguinetti thank financial support from FONCyT, PICT \#26113. M. Besfamille also thanks financial support from Fondation Maison des Sciences de l'Homme (Hermes grant).

${ }^{\dagger}$ Universidad Torcuato Di Tella and CONICET, Argentina. E-mail: larozamena@utdt.edu

${ }^{\ddagger}$ Universidad Torcuato Di Tella, Argentina. Corresponding author. E-mail: mbesfamille@utdt.edu

$\S$ Universidad Torcuato Di Tella, Argentina and Corporación Andina de Fomento, Venezuela. E-mail: sanguine@utdt.edu 


\section{Introduction}

For most governments, tax evasion is a problem because it threatens the equity and the efficiency of their fiscal policies (see Cowell 1985, and Skinner and Slemrod 1985). ${ }^{1}$ For this reason, governments react and adopt actions to ensure compliance with the tax law. For example, audits are conducted to verify whether tax liabilities have been met or not and, in the latter case, evaders are penalized.

However, this "enforcement approach" is not sufficient to deal with tax evasion. As the public finance literature shows, the fight against tax evasion cannot be isolated from the design of fiscal policy. The extent of tax evasion depends not only on the parameters that characterize the enforcement policy carried out (e.g. frequency of audits, level of fines) but also on the structure of the tax law (e.g. tax rates). Therefore, as suggested by Allingham and Sandmo (1972) and then emphasized by Kolm (1973), to design "optimal tax systems" (in Slemrod's (1990) terminology) governments should jointly determine tax and enforcement policies.

Since Sandmo (1981), many articles have analyzed, in different settings, such optimal tax-enforcement policies. ${ }^{2}$ These contributions share the following feature: governments or tax authorities can commit to the enforcement policy, in particular to the audit frequency (or probability). We believe that, as initially pointed out by Graetz et al. (1986), this assumption is very strong, for two reasons. First, it is hard to find evidence of a tax law that specifies the official enforcement strategy. Second, from a theoretical point of view, commitment requires that taxpayers observe whether the realization of an audit is in fact the result of the random policy to which the government has committed. Such observability seems very demanding.

To the best of our knowledge, there is no formal analysis of optimal tax and penalty schedules when the government cannot commit to its audit policy. ${ }^{3}$ The purpose of this paper is precisely to start filling this gap in the literature by presenting a simple, two-stage model with two key ingredients. First, the government lacks commitment capability, in the first stage, to its second-stage audit policy. Second, some of the taxpayers are honest, i.e. they always comply with the tax law $^{4}$-the remaining taxpayers are dishonest and, provided

\footnotetext{
${ }^{1}$ We can assess the quantitative importance of tax evasion by looking at the US example. The Internal Revenue Service (IRS) estimated a tax gap for tax year 2001 of U\$D 345 billion (IRS, 2006). This amounts to almost $15 \%$ of total tax revenue, which is far from negligible.

${ }^{2}$ Among others, we can cite Usher (1986), Slemrod and Yitzhaki (1987), Border and Sobel (1987), Mookherjee and Png (1989, 1990), Cremer, Marchand and Pestieau (1990), Kaplow (1990), Mayshar (1991), Sanchez and Sobel (1993), Pestieau, Possen and Slutsky (1994, 1998, 2004), Slemrod (1994), Cremer and Gahvari (1994, 1995), Marhuenda and Ortuño-Ortín (1997) and Chander and Wilde (1998).

${ }^{3}$ Melumad and Mookherjee (1989) find the optimal fiscal policy in a model where the government has "partial" commitment: it cannot commit to the audit strategy of the tax administration but can induce the latter to obtain some aggregate enforcement outcomes (e.g. total number of audits). This possibility, combined with the choice of the tax law and conditional wages (on these aforementioned aggregate outcomes), enable the government to restore the full-commitment optimum. But, as governments rarely have the prerogative to offer conditional wages (that should be observable to taxpayers), we prefer to consider the extreme possibility of no commitment to the audit policy.

${ }^{4}$ The existence of honest taxpayers has been recognized for a while in the economics literature on tax
} 
it is beneficial to them, they may evade taxes.

More specifically, we assume that there is a continuum of taxpayers, each of whom can be rich or poor, according to her earned income. The government taxes the rich in order to maximize social welfare and is also in charge of tax enforcement. In the first stage of the model, the government designs the tax law, which incorporates taxes and penalties for evaders. In the second stage, a report-audit game is played between taxpayers and the government. Taxpayers are requested to report their income and, then, for each report, the government decides whether to audit or not. Audits are perfect but costly. If a taxpayer is found to have misreported, the government sets the correct tax and levies a penalty according to the previously chosen tax law.

We want to have benchmarks that allow us to assess the impact of the government's lack of commitment. First, we obtain the optimal tax scheme under full information, where enforcement is worthless. Then, we find the optimal tax-enforcement scheme when the government can commit to all dimensions of its fiscal policy. As will happen in most cases studied in this paper, it turns out that our results crucially depend on the level of the audit cost. In particular, expected welfare is weakly decreasing in the audit cost, irrespective of how many honest taxpayers there are in the population.

Next, we solve the no-commitment model backwards. Depending on the tax law and the audit cost, two regimes may emerge as an equilibrium of the report-audit game that is played in the second stage of the model. A full-evasion regime may obtain, where the government does not audit and all rich dishonest taxpayers evade. Alternatively, we may have a partialevasion regime, where dishonest rich taxpayers randomly misreport their income and the government randomly audits individuals that have reported to be poor. We then move to the first stage and derive the optimal tax law, characterizing it as a function of the audit cost. For low levels of the audit cost, the government chooses taxes and penalties such that the partial-evasion regime emerges in the second stage. The tax is distorted downwards with respect to its optimal, full-information level, and fines are set at a level that is lower than the maximal legal limit that follows from limited liability. On the other hand, for higher levels of the audit cost, the government chooses a tax and penalty scheme that generates full evasion.

Although this result is intuitive, some features of the optimal tax law are striking. In particular, it may be optimal to set the penalty at its lowest level. Fining those evaders that are caught, just as setting higher taxes, provides incentives for the government to actually audit those who file low-income reports in the second stage, thus generating the partial-evasion regime. However, for some levels of the audit cost, auditing with a positive probability may be too costly for the government. It may be preferable to commit not to audit -i.e. to ensure full evasion. To do so, the government may lower fines and/or taxes. Since honest taxpayers always pay their taxes, reducing fines is the best option. Hence, fines may be set at their lowest possible level, and taxes at the highest level compatible with the

compliance. Among the first to acknowledge this, Spicer and Lundstedt (1976) point out that attitudes and norms do affect evasion decisions. Baldry (1986) reports that some people never evade, no matter the level of tax rates, audit probabilities or sanctions. According to Gordon (1989), Benjamini and Maital (1985) were the first to incorporate moral costs into a formal model of individual evasion decisions. 
full-evasion regime.

Furthermore, as long as some individuals are honest, expected social welfare is nonmonotonic in the audit cost. When commiting not to audit is desirable for the government, a higher audit cost makes doing so easier. Higher taxes, always paid by honest taxpayers, become compatible with full evasion. Consequently, taxes are optimally set closer to their full-information level. These results stress the fact that some of the intuitions in the theory of optimal tax enforcement may no longer be valid once we abandon the assumptions of full commitment and that every single taxpayer is strategic.

In the final part of the paper, we show that our results are robust to more general assumptions, and we provide a few extensions of our basic model.

\section{Related literature}

The paper is related to many strands in the literature. First of all, as we already mentioned in footnote 2 , there is now an important list of contributions that have characterized, in different settings, the optimal tax-enforcement policy under commitment. This list can be divided into two groups. In the first, the government delegates tax collection and enforcement to a tax administration that has its own objectives (e.g. to maximize net tax collection, instead of social welfare). In the second group, there is no tax administration and it is the government that enforces the tax law. In both groups of contributions, the optimal tax is distorted with respect to its optimal full-information level, as we also find. But, due to the absence of commitment and the presence of honest taxpayers, we find that sometimes fines should be eliminated, a result that never emerges in the full-commitment literature.

Our paper is also related to Graetz et al. (1986), Reinganum and Wilde (1986), Erard and Feinstein (1994), Landsberger et al. (2000) and Liang and Yang (2008). These contributions analyze equilibrium models of tax enforcement when the tax administration audits a fraction of reported incomes, not following a prescribed policy but instead maximizing its own criterion ex post. But none of these articles finds the optimal tax and penalty policy. We follow closely Graetz et al. (1986), simplifying their model so that poor agents do not pay taxes. Moreover, as in Erard and Feinstein (1994), we show that the existence of honest taxpayers changes the results of the model qualitatively, not merely quantitatively.

We are not the first to study optimal policies (contracts) when the government (principal) cannot commit to the audit probability. Although in different contexts, others have already found that some of the policy (contract) variables can be used as commitment devices to ensure an equilibrium where audits are effectively conducted. For example, Khalil (1997) obtains the optimal contract when a regulator can verify ex post whether a firm has "cheated" -i.e. produced a different level of output than the one intended for it. He finds that the regulator should optimally distort upwards the production level required from an inefficient firm, ${ }^{5}$ a result that is at odds with the incentive theory of regulation. Picard (1996) characterizes the equilibrium of a perfectly-competitive insurance market where opportunist policyholders may file fraudulent claims. To deter such misbehavior, insurers audit claims. He shows that equilibrium insurance contracts depend on whether insurers can cred-

\footnotetext{
${ }^{5}$ In a lender-borrowing setting, Khalil and Parigi (1998) obtain a similar result, where the loan size is increased above the full-commitment level.
} 
ibly commit or not to their audit strategies. Although these contributions acknowledged the existence of a no-audit regime, they reach no result similar to ours regarding the optimal policy (contract) that makes the no-audit regime emerge. Two reasons can explain this. First, Khalil (1997) does not incorporate an honest type into his model. Thus, the analysis of the no-audit regime is trivial. Second, even assuming that some agents are honest, Picard (1996) cannot obtain a nonmonotonic expected welfare profile, as we do. This is due to the fact that, in his article, the no-audit regime is characterized by no insurance contracts sold in equilibrium. The difference with our setup is clear: taxation enables the government to act -i.e. to tax the honest rich-, even in the no-audit regime, and this is what generates the nonmonotonicity in expected welfare.

Finally, our results are also related to the literature on optimal penalties in a context of tax evasion. Many contributions to this literature have presented arguments (summarized in Skinner and Slemrod (1985) and Mookherjee (1997)) that explain why the well-known Beckerian result does not hold -i.e. why optimal penalties are not set at their maximum legal limit. Our model presents another rationale for that: low fines emerge as a commitment device. Furthermore, we show that, under some parameter configurations, penalties should be optimally set at zero. To the best of our knowledge, there is no contribution that has found such a sharp result, not even in the optimal law enforcement literature (see Garoupa 1997, and Polinsky and Shavell 2000). ${ }^{6}$ Although this result may seem unrealistic, extremely low legislated penalties have been observed in practice. For example, Anderson and Carasciuc (2004) explain that, during the transition in Moldova, characterized by periods of high inflation, the government did not update the nominal value of fines for tax evaders, which then became merely symbolic.

The remainder of the paper is organized as follows. The next section describes the model and presents the benchmarks. Section 3 shows the optimal tax policy and enforcement under asymmetric information and no commitment. Section 4 discusses some extensions of the model and further results. Section 5 concludes. All proofs appear in the Appendix.

\section{The model}

There is a continuum of taxpayers of measure one. Each taxpayer $i$ has an individual income $y_{i}$, which is a random variable that takes values in the set $\left\{y_{p}, y_{r}\right\}$, with $y_{p}<y_{r}$. A taxpayer with income $y_{r}\left(y_{p}\right)$ is henceforth called "rich" ("poor"). Each taxpayer's income $y_{i}$ is her private information. All individual incomes are i.i.d., and the probability that $y_{i}=y_{p}$ for any given taxpayer $i$ is $\mu \in(0,1)$, which is common knowledge.

\footnotetext{
${ }^{6}$ Although in very different settings, Boadway et al. (1996) and Emons $(2004,2006)$ find that governments may choose not to penalize criminals. Boadway et al. (1996) characterize time-consistent sanctions, when the government cannot commit to their level. Ex post, sanctions are optimally set at zero because they play no role as deterrants. Our results differ from theirs since, in our model, the government can commit to the level of penalties. Despite this fact, they can be set at zero. The reason behind Emons' results is exactly the opposite to ours: penalties for repeat offenders may be optimally eliminated as a means to increase the sanction for first-time offenders (due to a limited-liability constraint), which in turn deters offenses overall; our rationale, on the contrary, is that not penalizing evaders acts as a commitment device not to audit.
} 
In addition, each taxpayer may be "honest" or "dishonest," and this is her private information as well. Dishonest taxpayers file their tax returns by choosing to report the income level that maximizes their expected utilities. In other words, they may lie provided it is beneficial to them. On the contrary, honest taxpayers file truthful reports. Any given rich taxpayer is dishonest with probability $\theta \in(0,1]$, and this is common knowledge -it will be clear later on that whether a poor taxpayer is honest or dishonest is irrelevant, so we ignore this issue.

Taxpayer $i$ 's utility function is

$$
W_{i}=u\left(q_{i}\right)+g
$$

where $q_{i}$ is the value of her private-good consumption and $g$ is the government's provision of a public good. The function $u($.$) is strictly increasing, strictly concave and satisfies the$ Inada conditions. We normalize $u(0)=0$, and we assume that $u^{\prime}\left(y_{r}\right) \in(0,1)$, so that interior solutions always obtain.

The government maximizes a utilitarian social welfare function. First, it sets taxes and chooses penalties for evaders who are caught. Then, it is in charge of tax collection and enforcement.

The interaction between the government and taxpayers is formalized as a game, which proceeds in two stages. In the first stage, the government chooses the pair $\left(t_{r}, f\right)$, the "tax law," where $t_{r}$ is the tax due for rich taxpayers and $f$ is the penalty imposed on those who misreport their incomes and are detected. Note that we assume only rich individuals must pay taxes and that, at this stage, the government cannot commit to the audit policy that it will conduct later on.

In the second stage, the government and taxpayers play a "report-audit" game. ${ }^{7}$ Each taxpayer $i$ first reports an income level $\widetilde{y}_{i}$. Then, the government decides whether to audit each individual report or not. Each audit $\operatorname{costs} c \geq 0$. We assume audits are perfect: they allow the government to find the exact income level of the audited individual. If a false report is detected, then the evader must pay the fine $f$ on top of the tax level that corresponds to her true income. ${ }^{8}$ We will assume ex-post limited liability. Then, it has to be the case that $t_{r}+f \leq y_{r}$. Finally, the government finances the provision of the public good with all revenues collected from taxpayers: taxes and fines, net of audit costs.

The assumptions of the model deserve some comments. As noted by Andreoni et al. (1998), "an unresolved question is whether cheaters should be given the same weight in the social criterion function as honest taxpayers." We follow the literature on tax evasion, which provides a positive answer. The use of utilities that are linear in the public good simplifies the characterization of the equilibrium in the report-audit game (see footnote 12). ${ }^{9}$ In addition,

\footnotetext{
${ }^{7}$ It may be the case that tax enforcement is carried out by a revenue-maximizing, independent agency. We analyze this case in Section 4.

${ }^{8} \mathrm{As}$ most of the literature on tax evasion, we do not allow for rewards for truthful reports. Exceptions to this assumption can be found in Border and Sobel (1987), Mookherjee and Png (1989) and Chander and Wilde (1998) among others.

${ }^{9}$ Such utility functions have been recently adopted in the public economics literature. See Ray and Vohra (2001) and Bloch and Zenginobuz (2006).
} 
assuming only two income levels and no taxation for the poor simplifies the presentation of our results. Even though these three assumptions may seem too strong, in Section 4 we explain why they are in fact not too restrictive. Finally, in this paper the government can commit to taxes and penalties but not to the audit probability. Boadway and Keen (1998) choose a different setup: the government can commit to the audit probability but not to the (capital income) tax rate. They explain this choice as follows: the audit probability is associated with the administrative efficiency of the tax authority and this is more difficult to modify than any tax scheme, as many observers assert. Although this association is realistic, we believe that we cannot conclude that a (perhaps irreversible) structure of the tax authority implies that the government can commit to its audit policy. Irrespective of the tax authority's efficiency, a government can always renege its announced audit policy and decrease the frequency of controls ex post, as is the issue in this paper. In Boadway and Keen (1998), on the contrary, the government would have incentives to raise the audit probability ex post, which may be difficult given the structure of the tax administration.

\subsection{Two benchmark cases: full information and commitment to an audit probability}

As we mentioned, the key aspects of the game described above are the facts that (i) taxpayers' income levels are private information, (ii) the government cannot commit to its audit policy, and iii) some rich taxpayers are honest. Before deriving the equilibrium of the resulting game, we would like to have benchmarks where each one of these three assumptions is absent. We briefly examine here the case where taxpayers' income levels are publicly known and the situation where the government can commit to an audit probability. Then, throughout the paper, we will analyze how the absence of honest taxpayers would affect the results.

First assume that income levels are publicly known. Audits are unnecessary, and fines irrelevant. The government will then choose the tax $t_{r}$ so as to maximize

$$
\mathbb{E} W=\mu u\left(y_{p}\right)+(1-\mu) u\left(y_{r}-t_{r}\right)+g
$$

subject to its budget constraint $g=(1-\mu) t_{r} \cdot{ }^{10}$ As the government's objective function is concave, the optimal full-information tax, $t_{r}^{*}$, is characterized by the first-order condition

$$
u^{\prime}\left(y_{r}-t_{r}^{*}\right)=1
$$

Given our assumptions, we have $0<t_{r}^{*}<y_{r}$. Let $\mathbb{E} W^{*}$ be the expected welfare level when the government chooses the optimal full-information tax $t_{r}^{*}$.

Now assume that income levels are private information but the government can commit, in the first stage of the game, to audit with some probability $\beta$ when an individual has reported a low income level, $y_{p}$. Let $t_{r}^{c}, f^{c}$ and $\beta^{c}$ be the values that solve this problem. As

\footnotetext{
${ }^{10}$ Measurability issues arise in probability spaces with a continuum of i.i.d. random variables, as it is the case in our setting. In spite of this, we will adopt throughout the paper the usual abuse of the Law of Large Numbers.
} 
happens in Pestieau et al. (1998, 2004), two regimes emerge. First, when $c$ is relatively low, the government does enforce the tax law. Under this first regime, the revelation principle applies (see Mookherjee and Png 1990). Thus, the optimal fiscal policy solves the following problem

$$
\left\{\begin{array}{l}
\underset{t_{r}, f, \beta}{\operatorname{Max}} \mu u\left(y_{p}\right)+(1-\mu) u\left(y_{r}-t_{r}\right)+g \\
\text { subject to } \\
u\left(y_{r}-t_{r}\right) \geq(1-\beta) u\left(y_{r}\right)+\beta u\left(y_{r}-t_{r}-f\right) \\
g=(1-\mu) t_{r}-\mu \beta c \\
t_{r}+f \leq y_{r} \\
\beta \in[0,1]
\end{array}\right.
$$

The first constraint imposes, as usual, incentive compatibility, and the second is the government's budget constraint, which now incorporates the aggregate audit cost. At the optimum, the government completely deters evasion by setting the maximal penalty $f^{c}=y_{r}-t_{r}^{c}$ and by auditing low-income reports with the audit probability

$$
\beta^{c}=1-\frac{u\left(y_{r}-t_{r}^{c}\right)}{u\left(y_{r}\right)} .
$$

The optimal tax is given by the following first-order condition:

$$
u^{\prime}\left(y_{r}-t_{r}^{c}\right)=\frac{1}{1+\frac{\mu}{1-\mu} \frac{c}{u\left(y_{r}\right)}}<1 .
$$

If $c$ goes to zero, $t_{r}^{c}$ converges to the optimal full-information tax $t_{r}^{*}$. Moreover, it can be easily verified that $t_{r}^{c}$ decreases with $c$. The government distorts $t_{r}^{c}$ downwards with respect to $t_{r}^{*}$ in order to reduce the stake for evasion and, thereby, the audit probability. This attenuates the increase in the aggregate audit cost due to the rise in $c$.

When auditing becomes more costly, the government gives up enforcing the tax law, i.e. it sets $\beta^{c}=0$. In this case, assuming - as we do- that there may exist honest taxpayers becomes very relevant. When all rich taxpayers are dishonest $(\theta=1)$, the government collects no taxes, so we can assume without loss of generality that it chooses $t_{r}^{c}=0$, obtaining a level of expected welfare denoted by $\mathbb{E} W^{N T}$. On the other hand, when some of the rich are honest $(\theta<1)$, the government can collect taxes from them. ${ }^{11}$ Thus, it solves

$$
\left\{\begin{array}{l}
\underset{t_{r}, f}{\operatorname{Max}} \mu u\left(y_{p}\right)+(1-\mu) \theta u\left(y_{r}\right)+(1-\mu)(1-\theta) u\left(y_{r}-t_{r}\right)+g \\
\text { subject to } \\
g=(1-\mu)(1-\theta) t_{r}
\end{array}\right.
$$

\footnotetext{
${ }^{11}$ In this case, there is no complete revelation of individual types. The government does not have enough instruments to screen between honest and dishonest rich taxpayers, so the latter misreport. For similar results, albeit in different contexts, see Kofman and Lawarrée (1996) and Picard (1996).
} 
The objective function is -but for a constant factor that does not affect the solution- the same as under full information. Therefore the government optimally sets $t_{r}^{c}=t_{r}^{*}$ while the level of the penalty is irrelevant.

Figures 1(a) and 1(b) below depict the expected welfare $\mathbb{E} W^{c}$ as a function of the audit cost when commitment is possible.

$$
\theta=1 \quad \theta<1
$$

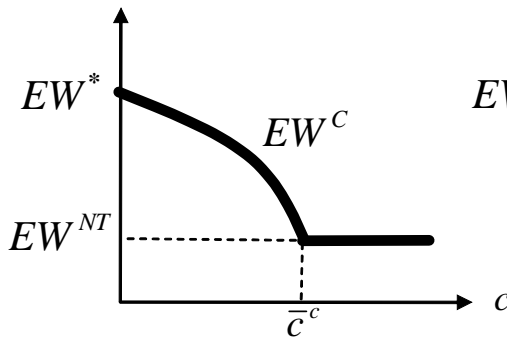

Figure1(a)

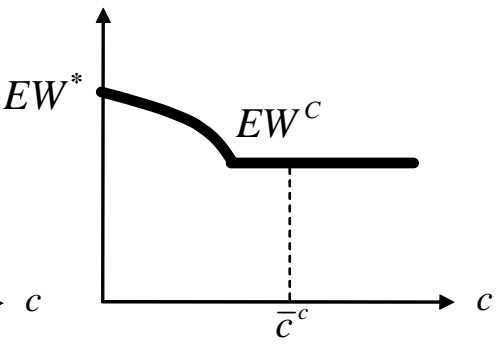

Figure 1(b)

Figures 1: Expected welfare under full commitment

Expected welfare takes its full-information level $\mathbb{E} W^{*}$ when $c=0$, then it is continuous and weakly decreasing in $c$. In Figure 1(a), the shift of regimes occurs when

$$
c=\bar{c}^{c} \equiv \frac{(1-\mu)}{\mu} \frac{u\left(y_{r}\right)\left(1-u^{\prime}\left(y_{r}\right)\right)}{u^{\prime}\left(y_{r}\right)} .
$$

However, as long as there are some honest rich taxpayers (i.e. $\theta<1$ ), the fact that the government can collect taxes from them causes the no-audit regime to emerge for values of $c$ lower than $\bar{c}^{c}$, as shown in Figure 1(b). This is the only difference between the two figures.

\section{Tax policy and enforcement under asymmetric infor- mation and no commitment}

We return now to the full game described above. Our aim is to characterize the optimal tax law when, in the first stage, the government anticipates the equilibrium that will result from its second-stage interaction with taxpayers. We solve this problem backwards, starting with the report-audit game. 


\subsection{The equilibrium of the report-audit game}

Once the government has chosen a tax law $\left(t_{r}, f\right)$, its interaction with taxpayers may be described by the game depicted in the following figure.

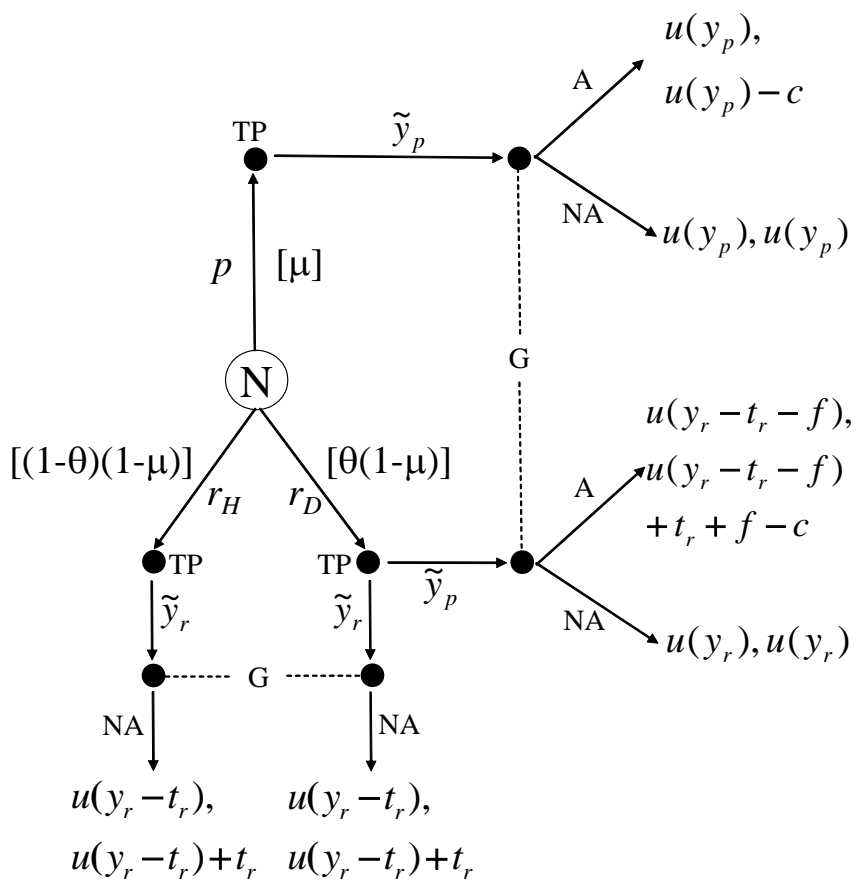

Figure 2: Extensive form of the report-audit game

In the game tree, TP $(\mathrm{G})$ denotes the taxpayer (government), $p$ denotes a poor individual, and $r_{D}\left(r_{H}\right)$ stands for a dishonest (honest) type for the rich taxpayer. The payoffs after each terminal node respectively correspond to the taxpayer and the government. Since the distribution of taxpayers is atomless, none of them takes into account any impact of their choices on public good provision: they just care about their own consumption. ${ }^{12}$

In addition, as we mentioned above, since poor taxpayers are not taxed, distinguishing between an honest and a dishonest type is irrelevant in their case, so that possibility is ignored in the tree.

Assume initially that $t_{r}>0, f>0$. The following proposition characterizes the perfect Bayesian equilibria (PBE) of this game.

Proposition 1 Let $\widetilde{c}=\frac{(1-\mu) \theta}{(1-\mu) \theta+\mu}\left(t_{r}+f-\left[u\left(y_{r}\right)-u\left(y_{r}-t_{r}-f\right)\right]\right)$ denote the value of the audit cost that makes the government indifferent between auditing and not auditing when a dishonest rich taxpayer always misreports.

- If $c>\widetilde{c}$, there is a unique PBE where the government never audits and a dishonest rich taxpayer always misreports.

\footnotetext{
${ }^{12}$ Here is where the linearity of taxpayers' utility functions in the public good greatly simplifies the analysis: the effect of each taxpayer's contribution on her own utility through the level of public good provision is independent of other taxpayers' behavior.
} 
- If $c<\widetilde{c}$, there is a unique PBE in mixed strategies, in which the government audits each announcement $\widetilde{y}_{i}=y_{p}$ with probability

$$
0<\widehat{\beta}=\frac{u\left(y_{r}\right)-u\left(y_{r}-t_{r}\right)}{u\left(y_{r}\right)-u\left(y_{r}-t_{r}-f\right)}<1,
$$

and a dishonest rich taxpayer misreports with probability

$$
0<\widehat{\pi}=\frac{\mu c}{(1-\mu) \theta\left(t_{r}+f-c-\left[u\left(y_{r}\right)-u\left(y_{r}-t_{r}-f\right)\right]\right)}<1 .
$$

- If $c=\widetilde{c}$, there is a continuum of PBE in mixed strategies, in which the government audits each announcement $\widetilde{y}_{i}=y_{p}$ with a probability $\beta \in[0, \widehat{\beta}]$, and a dishonest rich taxpayer always misreports. ${ }^{13}$

Leaving aside the borderline case where $c=\widetilde{c}$, Proposition 1 asserts that one of two situations will arise, depending on the audit cost. If $c>\widetilde{c}$, the government never audits and dishonest taxpayers always misreport. A "full-evasion" regime obtains, denoted by $R^{F E}$. If $c<\widetilde{c}$, however, a "partial-evasion" regime emerges, which we will denote by $R^{P E}$. In this case, there is a mixed-strategy equilibrium of the report-audit game. The government audits any report of a low income level with probability $\widehat{\beta}$-which leaves dishonest rich taxpayers indifferent between misreporting and reporting truthfully. Dishonest taxpayers misreport with probability $\widehat{\pi}$, which makes the government - given the updated probabilities it attaches to the taxpayer being rich or poor- indifferent between auditing and not doing so. See the Appendix for details. ${ }^{14}$

These results differ from those in Graetz et al. (1986), since in their model enforcement is carried out by a tax administration whose goal is to maximize net tax collection. Therefore, their equilibrium probability of misreport only takes into account the monetary benefits and costs of auditing. Here, as the (utilitarian) government directly enforces the tax law, it also takes into account taxpayers' welfare. Therefore, the equilibrium probability of misreport also incorporates the decrease in utility suffered by a caught evader.

\subsection{The optimal tax law}

We move back now to the first stage, where the government sets the tax law anticipating the resulting equilibrium in the report-audit game. Let $\Omega=\left\{\left(t_{r}, f\right): t_{r}+f \leq y_{r}\right\}$ denote the set of tax laws that satisfy ex-post limited liability. As noted above, different regimes may emerge, and the exact choice of $\left(t_{r}, f\right)$ affects the threshold $\widetilde{c}$ that separates one regime from

\footnotetext{
${ }^{13}$ In all these equilibria, the government is indifferent between any audit probabilities and the behavior of dishonest taxpayers is the same as if $\beta=0$.

${ }^{14}$ If $f=0$, misreporting is a weakly dominant strategy for dishonest rich taxpayers. Hence, they will always misreport, except perhaps when the government audits low-income reports with probability one. Then, there is no substantial change in the results stated in Proposition 1. See footnote 23 below for the case where $t_{r}=0$.
} 
the other. Thus, the government should identify the subsets of pairs $\left(t_{r}, f\right) \in \Omega$ that give rise to each regime, then find the pairs that maximize expected welfare within each subset, and, finally, compare the maximum attainable expected welfare levels under both regimes to make the final choice. Next, we follow these steps.

\subsubsection{Regime $R^{F E}$}

It may seem a priori odd to analyze the optimal tax law in a regime where there will be no enforcement. When $\theta=1$, this is certainly true: provided that regime $R^{F E}$ emerges, $t_{r}$ and $f$ are irrelevant, since the government will collect no taxes. Recall, however, that there may exist honest rich taxpayers -i.e. $\theta<1$. In such a case, as these individuals are the only source of revenue under this regime, specifying the tax they will pay is relevant. Expected welfare is given by

$$
\mathbb{E} W^{F E}=\mu u\left(y_{p}\right)+(1-\mu) \theta u\left(y_{r}\right)+(1-\mu)(1-\theta) u\left(y_{r}-t_{r}\right)+g
$$

where $g=(1-\mu)(1-\theta) t_{r}$. Replacing the government's budget constraint into the objective function, the government's problem, denoted by $\mathcal{P}^{F E}$, is as follows

$$
\mathcal{P}^{F E}\left\{\begin{array}{l}
\underset{t_{r}, f}{M a x} \quad \mu u\left(y_{p}\right)+(1-\mu) \theta u\left(y_{r}\right)+(1-\mu)(1-\theta)\left[u\left(y_{r}-t_{r}\right)+t_{r}\right] \\
\text { subject to } \\
\left(t_{r}, f\right) \in \Omega \\
c \geq \frac{(1-\mu) \theta}{(1-\mu) \theta+\mu}\left(t_{r}+f-\left[u\left(y_{r}\right)-u\left(y_{r}-t_{r}-f\right)\right]\right)
\end{array}\right.
$$

The second constraint ensures that the government is choosing a tax law that actually generates regime $R^{F E} .^{15}$ Let $\left(\widehat{t}_{r}^{F E}, \widehat{f}^{F E}\right)$ be the solution to problem $\mathcal{P}^{F E}$. The following proposition completely characterizes it.

Proposition 2 Let $c_{1}=\frac{(1-\mu) \theta}{(1-\mu) \theta+\mu}\left(t_{r}^{*}-\left[u\left(y_{r}\right)-u\left(y_{r}-t_{r}^{*}\right)\right]\right)$. Then,

- If $c \geq c_{1}, \widehat{t}_{r}^{F E}=t_{r}^{*}$ and $\widehat{f}^{F E} \in[0, \bar{f}]$.

- If $0<c<c_{1}, \widehat{t}_{r}^{F E}<t_{r}^{*}$ and $\widehat{f}^{F E}=0$.

The intuition for this result is as follows. If we ignored the second constraint in $\mathcal{P}^{F E}$, the government's objective function would again be -but for a constant factor that does not affect the solution- the same as under full information. Then it would be optimal to set $t_{r}=t_{r}^{*}$. If $c \geq c_{1}$, this is indeed possible: the government optimally chooses $t_{r}^{*}$, combined with a fine low enough so that regime $R^{F E}$ emerges. In the Appendix we show that the

\footnotetext{
${ }^{15}$ If this constraint holds with equality, as we mentioned above, there is a continuum of PBEs. To avoid technical complications, we assume here that, under such circumstances, the equilibrium where the government never audits is selected.
} 
upper bound $\bar{f}$ is below the maximal legal limit $y_{r}-t_{r}^{*}$. In choosing a low enough fine, the government commits not to audit low-income reports.

However, if $c<c_{1}$, it is not possible to set $t_{r}=t_{r}^{*}, f>0$ and generate regime $R^{F E}$. With this tax level, as the audit cost is relatively low, if all dishonest rich taxpayers misreported their incomes, then the government's optimal response would be to audit low-income reports: an equilibrium in mixed strategies would obtain, as in regime $R^{P E}$. Therefore, if the government wishes to stay within regime $R^{F E}$, it is optimal for it to set the highest $\operatorname{tax}^{16}$ compatible with the second constraint and no punishment for detected misreporters. Intuitively, the government can reduce taxes and/or lower fines to ensure full evasion: any of these actions reduces incentives to audit in the second stage. But lowering fines is always better for the government, since fines will never be collected under full evasion, whereas honest taxpayers always pay their taxes. Therefore, fines will be set at zero and taxes will be set at the maximum level compatible with regime $R^{F E}$.

In addition, we prove in the Appendix that the optimal tax $\widehat{t}_{r}^{F E}$ satisfies $\lim _{c \rightarrow 0} \widehat{t}_{r}^{F E}=0$, and increases with $c$. Clearly, a rise in $c$ enables the government to set $t_{r}$ at a higher level and still have no incentive to audit in the second stage. When $c$ vanishes, however, audits will follow even from arbitrarily small taxes, so only $\widehat{t}_{r}^{F E}=0$ remains compatible with full evasion.

Considering the optimal taxes and fines in each possible case, it follows that the highest welfare level attainable under regime $R^{F E}$ is

$$
\mathbb{E} W^{F E}= \begin{cases}\mu u\left(y_{p}\right)+(1-\mu) \theta u\left(y_{r}\right)+(1-\mu)(1-\theta)\left[u\left(y_{r}-\widehat{t}_{r}^{F E}\right)+\widehat{t}_{r}^{F E}\right] & \text { if } c<c_{1} \\ \mu u\left(y_{p}\right)+(1-\mu) \theta u\left(y_{r}\right)+(1-\mu)(1-\theta)\left[u\left(y_{r}-t_{r}^{*}\right)+t_{r}^{*}\right] & \text { if } c \geq c_{1}\end{cases}
$$

If $0<c<c_{1}$, we show in the Appendix that $\mathbb{E} W^{F E}$ increases linearly with $c .{ }^{17}$ This is because a higher audit cost enables, as we have just explained, to levy higher taxes and still remain under regime $R^{F E}$. When $c \geq c_{1}$, though, $\mathbb{E} W^{F E}$ is constant in $c$ : once the optimal full-information tax can be set within regime $R^{F E}$, further increases in the audit cost have no welfare effects. Figures 3 below depict expected welfare as a function of the audit cost when the government wishes regime $R^{F E}$ to emerge.

\footnotetext{
${ }^{16}$ Given that we are considering taxes that are lower than $t_{r}^{*}$, and since the full-information problem is concave, expected welfare is increasing in $t_{r}$. Hence, the government chooses the highest possible value for $t_{r}$.

${ }^{17}$ The reasoning in footnote 16 applies here as well.
} 
$\theta<1$

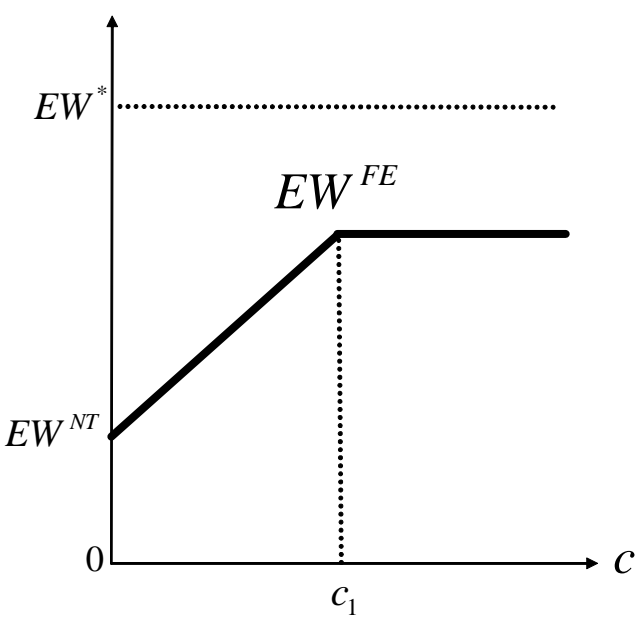

Figure 3(a)

$\theta=1$

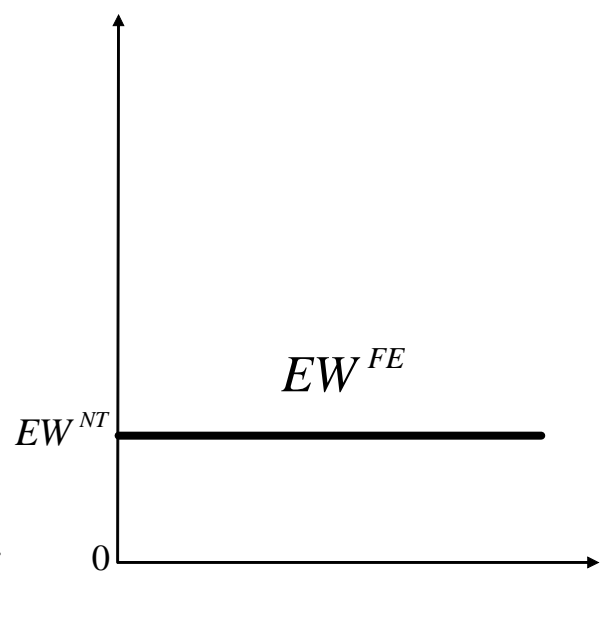

Figure 3(b)
C

Figures 3: Expected welfare under regime $R^{F E}$

As is intuitive, $\mathbb{E} W^{F E}=\mathbb{E} W^{N T}$ when $\theta=1$. But as long as $\theta<1, \mathbb{E} W^{F E}$ is higher.

\subsubsection{Regime $R^{P E}$}

We consider now the case where the government wishes to generate the partial-evasion equilibrium at the second stage. To do so, it must then choose a pair $\left(t_{r}, f\right)$ such that $c \leq \widetilde{c}=\frac{(1-\mu) \theta}{(1-\mu) \theta+\mu}\left(t_{r}+f-\left[u\left(y_{r}\right)-u\left(y_{r}-t_{r}-f\right)\right]\right)$. Expected welfare is then

$$
\begin{aligned}
\mathbb{E} W^{P E}= & \widehat{\beta} \widehat{\nu}\left[\frac{\mu}{\widehat{\nu}} u\left(y_{p}\right)+\frac{(1-\mu) \theta \widehat{\pi}}{\widehat{\nu}} u\left(y_{r}-t_{r}-f\right)\right]+(1-\widehat{\beta}) \widehat{\nu}\left[\frac{\mu}{\widehat{\nu}} u\left(y_{p}\right)+\frac{(1-\mu) \theta \widehat{\pi}}{\widehat{\nu}} u\left(y_{r}\right)\right] \\
& +(1-\widehat{\nu}) u\left(y_{r}-t_{r}\right)+g
\end{aligned}
$$

where $\widehat{\nu}=\mu+(1-\mu) \theta \widehat{\pi}$ is the probability that any taxpayer $i$ makes an announcement $\widetilde{y}_{i}=y_{p}$ and

$$
g=\widehat{\beta} \widehat{\nu}\left[\frac{(1-\mu) \theta \widehat{\pi}}{\widehat{\nu}}\left(t_{r}+f-c\right)-\frac{\mu}{\widehat{\nu}} c\right]+(1-\widehat{\nu}) t_{r}
$$

is the government's budget constraint. Replacing $\widehat{\beta}$ and $\widehat{\pi}$ according to (1) and (2),

$$
\begin{aligned}
\mathbb{E} W^{P E}= & \mu u\left(y_{p}\right)+(1-\mu) u\left(y_{r}-t_{r}\right) \\
& +(1-\mu)(\underbrace{1-\frac{\mu c}{(1-\mu)\left[t_{r}+f-c-\left(u\left(y_{r}\right)-u\left(y_{r}-t_{r}-f\right)\right)\right]}}_{1-\theta \widehat{\pi}} t_{r}
\end{aligned}
$$


where the last term follows from the government's budget constraint. The provision of the public good equals $(1-\mu)(1-\theta \widehat{\pi}) t_{r}$, the amount of taxes collected upon those rich who do not misreport. ${ }^{18}$

Two observations can be made. First, the fraction of dishonest rich taxpayers $\theta$ has no effect on expected welfare ${ }^{19}$-as long as, of course, it remains positive. The reason for this is as follows. At the mixed-strategy equilibrium of the report-audit game, the government will be indifferent between auditing a low-income report and not doing so. When auditing, the government pays a cost $c$ and faces, with probability $\mu / \widehat{\nu}(1-\mu / \widehat{\nu})$ a poor (respectively, dishonest rich) taxpayer. When the taxpayer is poor, the government gains nothing. If the taxpayer is rich and dishonest, the government generates a change in welfare (net of the audit cost) of

$$
t_{r}+f-c-\left[u\left(y_{r}\right)-u\left(y_{r}-t_{r}-f\right)\right],
$$

which does not depend on $\theta$. Given that not auditing always pays zero, when $\theta$ rises the government can only remain indifferent if $\mu / \widehat{\nu}$ stays constant. This, in turn, implies that $\theta \widehat{\pi}$ cannot vary. Therefore, in equilibrium, the increase in $\theta$ is exactly offset by the decrease in $\widehat{\pi}$, making aggregate tax evasion and thus, tax collection, constant. Moreover, $\widehat{\beta}$ is the audit probability that makes a dishonest rich taxpayer indifferent between reporting truthfully and misreporting. So her equilibrium expected utility will be $u\left(y_{r}-t_{r}\right)$, which is the same as the utility for an honest rich taxpayer. Hence, from the point of view of an utilitarian government, the expected utility before observing taxpayers' reports is $\mu u\left(y_{p}\right)+(1-\mu) u\left(y_{r}-t_{r}\right)$. In spite of the fact that expected welfare is independent of $\theta$, this parameter does have an impact on the choice of the optimal tax law under regime $R^{P E}$, as we will see below.

Second, neither the audit cost $c$ nor the fine $f$ appear in (4) except in the very last term. In fact, extra taxes and fines just cover the audit cost. Therefore, as stated by Landsberger et al. (2000), the enforcement of the tax law only contributes to tax collection indirectly, via the reporting strategies of dishonest rich taxpayers.

To find the optimal tax law under regime $R^{P E}$, the government solves the following problem, denoted by $\mathcal{P}^{P E}$.

$$
\mathcal{P}^{P E}\left\{\begin{array}{l}
\underset{t_{r}, f}{\operatorname{Max}} \quad \mu u\left(y_{p}\right)+(1-\mu) u\left(y_{r}-t_{r}\right)+(1-\mu)(1-\theta \widehat{\pi}) t_{r} \\
\text { subject to } \\
\left(t_{r}, f\right) \in \Omega \\
\widehat{\pi}=\frac{\mu c}{(1-\mu) \theta\left(t_{r}+f-c-\left[u\left(y_{r}\right)-u\left(y_{r}-t_{r}-f\right)\right]\right)} \\
c \leq \frac{(1-\mu) \theta}{(1-\mu) \theta+\mu}\left(t_{r}+f-\left[u\left(y_{r}\right)-u\left(y_{r}-t_{r}-f\right)\right]\right)
\end{array}\right.
$$

\footnotetext{
${ }^{18} \widehat{\pi}$ is the probability that makes the government indifferent between auditing and not auditing an announcement $\widetilde{y}_{i}=y_{p}$. Then, as the government's equilibrium expected tax collection will be, after observing $\widetilde{y}_{i}=y_{p}$, equal to 0 , the expected tax collection before observing taxpayers' report is $[\mu+(1-\mu) \theta \widehat{\pi}] .0+(1-\mu)(1-\theta \widehat{\pi}) t_{r}$.

${ }^{19}$ Despite the differences between the two models, this comparative statics result coincides with the one obtained in Graetz et al. (1986).
} 
Again, the last constraint ensures that the government is choosing a tax law that actually generates regime $R^{P E} \cdot{ }^{20}$ Let the solution to this problem be $\left(\widehat{t}_{r}^{P E}, \widehat{f}^{P E}\right)$. In the Appendix, we prove that, although the objective function of this problem is not globally concave, the second-order conditions hold, and thus the first-order conditions are also sufficient to characterize the maximum. Then, applying the Implicit Function Theorem, we can carry out some comparative statics exercises with respect to the audit cost $c$ and completely characterize the profile of the optimal tax law.

At the optimum, the government seeks to attenuate individual tax evasion by reducing its stake. This is usual in the optimal tax-enforcement literature, which assumes full commitment. The novelty here is that the ex-post limited-liability constraint does not bind: $\widehat{t}_{r}^{P E}+\widehat{f}^{P E}=t_{r}^{*}<y_{r}$, a result that does not depend upon the fraction of honest taxpayers $\theta$. This is intuitive, since we have mentioned above that this fraction does not influence equilibrium expected welfare. Given that it is the government - which cares about evaders' welfare - that performs audits ex post, without being able to commit to their frequency, the fine is not set at the maximal legal limit.

Why does $\widehat{t}_{r}^{P E}+\widehat{f}^{P E}$ amount to the optimal full-information tax? At the second stage, when the government decides on enforcement, the net benefit from auditing a low income report is, as we mentioned above, $t_{r}+f-c-\left[u\left(y_{r}\right)-u\left(y_{r}-t_{r}-f\right)\right]$. When in the first stage the government seeks to reduce the stake for (individual) evasion, this is achieved by maximizing this net benefit. Note, however, that the part of this net benefit under the control of the government depends only upon $t_{r}+f$ and has the same structure as the government's objective function under full information. Therefore, the government optimally sets $\widehat{t}_{r}^{P E}+\widehat{f}^{P E}=t_{r}^{*}$.

This has two important consequences. First, the last constraint in program $\mathcal{P}^{P E}$ may be binding; as is the case when $c \geq c_{1}$. Second, even though the government cannot commit to its audit strategy, the optimal tax law (indirectly) fixes the level of (individual and aggregate) evasion at the equilibrium in the second stage. The aggregate level of evasion is $(1-\mu) \theta \widehat{\pi}=\frac{\mu c}{\left(t_{r}^{*}-\left[u\left(y_{r}\right)-u\left(y_{r}-t_{r}^{*}\right)\right]\right]}$, which depends only upon parameters of the model. In particular it increases with the audit cost $c$. Therefore, the exact value of the optimal tax $\widehat{t}_{r}^{P E}$ will not have an impact on the equilibrium aggregate level of tax evasion.

The next proposition completely characterizes the tax profile.

Proposition 3 Let $\widehat{c}=\frac{(1-\mu)\left[1-u^{\prime}\left(y_{r}\right)\right]}{1-(1-\mu) u^{\prime}\left(y_{r}\right)}\left(t_{r}^{*}-\left[u\left(y_{r}\right)-u\left(y_{r}-t_{r}^{*}\right)\right]\right)$ and $\widehat{\theta}=1-u^{\prime}\left(y_{r}\right)$.

- Case $A: \theta \leq \widehat{\theta} \Leftrightarrow c_{1} \leq \widehat{c}$.

When $0<c<c_{1}, \widehat{t}_{r}^{P E}$ verifies $\lim _{c \rightarrow 0} \widehat{t}_{r}^{P E}=t_{r}^{*}, \frac{\partial \hat{t}_{r}^{P E}}{\partial c}<0$ and $\lim _{c \rightarrow c_{1}} \widehat{t}_{r}^{P E}=t_{r}^{\prime}>0$. When $c \geq c_{1}, \widehat{t}_{r}^{P E}=t_{r}^{\prime}$.

\footnotetext{
${ }^{20}$ If the last constraint holds with equality there is a continuum of PBEs in the report-audit game. To avoid technical complications, we assume now that the equilibrium is selected where the government audits with probability $\widehat{\beta}$. As we will point out below, this assumption - just as the previous one under full evasioncould be modified without altering our results.
} 
- Case B: $\theta>\widehat{\theta} \Leftrightarrow c_{1}>\widehat{c}$.

When $0<c<\widehat{c}, \widehat{t}_{r}^{P E}$ verifies $\lim _{c \rightarrow 0} \widehat{t}_{r}^{P E}=t_{r}^{*}, \frac{\partial \hat{t}_{r}^{P E}}{\partial c}<0$ and $\lim _{c \rightarrow \widehat{c}} \widehat{t}_{r}^{P E}=0$. When $c \geq \widehat{c}$, the optimal tax is $\widehat{t}_{r}^{P E}=0$.

This proposition is most easily understood with reference to Figures 4, which depict the profiles of the optimal tax $\widehat{t}_{r}^{P E}$.

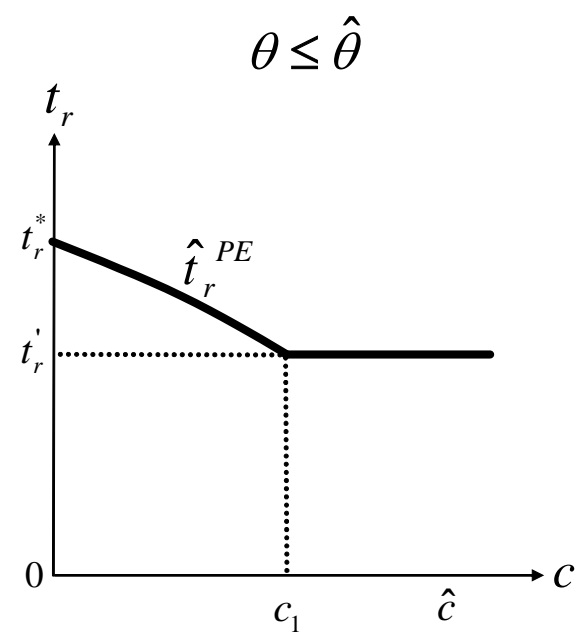

Figure 4(a)

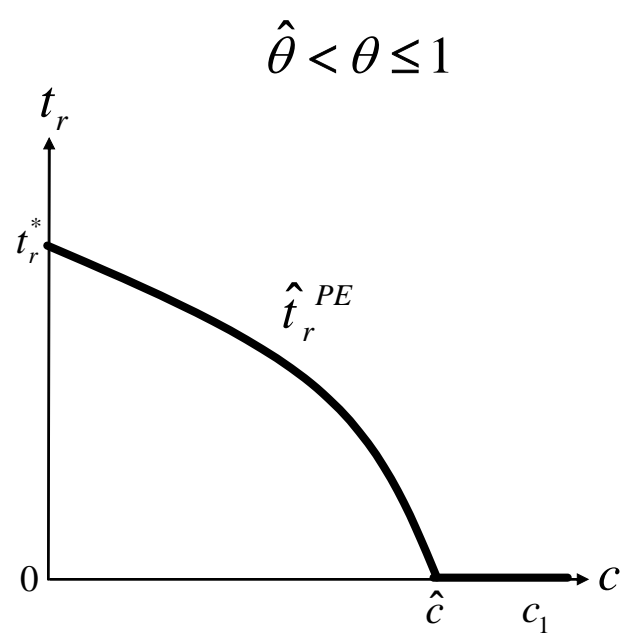

Figure 4(b)

Figures 4: Optimal tax under regime $R^{P E}$

In both cases, the optimal tax $\widehat{t}_{r}^{P E}$ is lower than the optimal full-information tax $t_{r}^{*}$ and it weakly decreases with $c .{ }^{21}$ The intuition is as follows. Clearly, when $c=0$, there will be no misreporting and the government will set a tax $t_{r}^{*}$. Assume for convenience that, in this case, $f=0$. When $c$ becomes positive, though, equilibrium play in the "report-audit" game shifts to mixed strategies. As $c$ grows, as noted above, so does $\widehat{\pi}$ and thus tax collection falls. This means that the marginal contribution of the tax level $t_{r}$ to welfare through public good provision falls. In order to restore first-stage optimality, the marginal cost of the tax level in terms of the rich taxpayer's private consumption has to go down as well. The government's optimal reaction is then to lower $t_{r}$ (while raising $f$, so as to keep their sum equal to $t_{r}^{*}$ ). Hence the decrease in welfare due to the increase in the audit cost is attenuated with a tax below the full-information one. The same argument explains why the tax distortion grows with $c,{ }^{22}$ until $c=c_{1}$. For higher audit costs, a limit result for regime $R^{P E}$ obtains. The government chooses taxes and fines so that $c=\widetilde{c}$ : dishonest rich taxpayers misreport with

\footnotetext{
${ }^{21}$ Unfortunately, for a given value of the audit cost $c$, the comparison between $t_{r}^{c}$ and $\widehat{t}_{r}^{P E}$, the optimal tax under full commitment and effective enforcement, depends on parameter values and on the curvature of the utility function. This is due to the fact that the government faces a different trade-off in each case. Under full commitment, a change in $t_{r}^{c}$ affects both tax collection from all rich taxpayers and the aggregate audit cost. Without commitment, a change in $\widehat{t}_{r}^{P E}$ only impacts the amount paid by honest rich taxpayers.

${ }^{22}$ The distortion is measured by the difference $t_{r}^{*}-\widehat{t}_{r}^{P E}$.
} 
probability one, and the government is indifferent between auditing low-income reports and not doing so. As shown in the Appendix, this implies that the $\operatorname{tax} \widehat{t}_{r}^{P E}=t_{r}^{\prime}$ is independent of $c$ and thus, the tax profile becomes flat.

When $\theta$, the probability that a given rich taxpayer is dishonest, is small, case $\mathrm{A}$, as displayed in Figure 4(a), obtains. The optimal tax $\widehat{t}_{r}^{P E}$ is always strictly positive. But this does not always hold. As $c_{1}$ grows with $\theta$, if $\theta$ becomes large enough eventually $(\theta \geq \widehat{\theta})$ we will have $c_{1} \geq \widehat{c}$. This happens in case $\mathrm{B}$, and is shown in Figure 4(b). There, when $c \in\left[\widehat{c}, c_{1}\right]$, the marginal contribution of $t_{r}$ to welfare through public good provision is lower than its cost in terms of private consumption even at $t_{r}=0$. Audits are just too costly for the government to even want to induce itself to play an equilibrium in mixed strategies in the "report-audit" game. Thus, it is optimal for the government to generate a new "no taxation" regime, which we will denote by $R^{N T}{ }^{23}$ When $c \geq c_{1}$, this "no taxation" regime obtains, with $t_{r}^{\prime}=0$.

Taking into account the optimal tax and fine levels, we can obtain the profile of expected welfare under regime $R^{P E}$ :

$$
\mathbb{E} W^{P E}= \begin{cases}\mu u\left(y_{p}\right)+(1-\mu) u\left(y_{r}-\widehat{t}_{r}^{P E}\right)+(1-\mu)(1-\theta \widehat{\pi}) \widehat{t}_{r}^{P E} & \text { if } c \leq \min \left\{c_{1}, \widehat{c}\right\} \\ \mu u\left(y_{p}\right)+(1-\mu) u\left(y_{r}-t_{r}^{\prime}\right)+(1-\mu)(1-\theta \pi) t_{r}^{\prime} & \text { if } c>\min \left\{c_{1}, \widehat{c}\right\}\end{cases}
$$

When $c \leq \min \left\{c_{1}, \widehat{c}\right\}$, it is straightforward to prove, using an envelope argument, that $\mathbb{E} W^{P E}$ decreases with $c$. When $c>\min \left\{c_{1}, \widehat{c}\right\}, \mathbb{E} W^{P E}$ is constant and equal to $\mathbb{E} W^{\prime}$ (i.e. the welfare level with $t_{r}^{\prime}>0$ ) or to the welfare level without taxation $\mathbb{E} W^{N T}$. The welfare profiles that correspond to cases A and B of Proposition 3 may be visualized in Figures 5 below.

$$
\theta \leq \hat{\theta} \quad \hat{\theta}<\theta \leq 1
$$
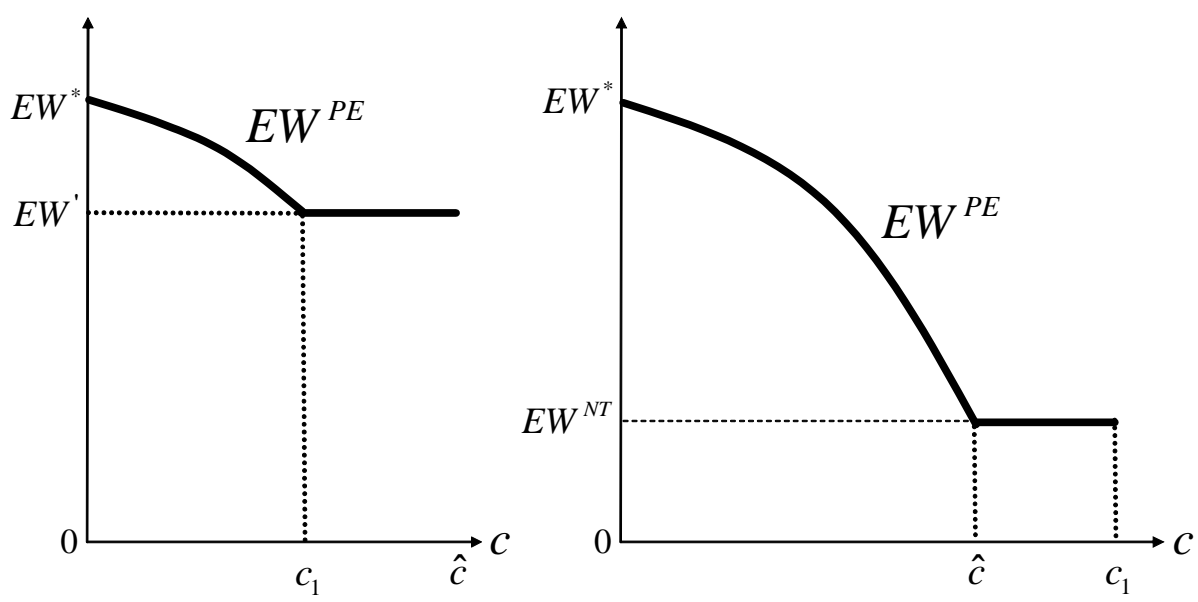

Figures 5: Expected welfare under regime $R^{P E}$

\footnotetext{
${ }^{23}$ In the description of the "report-audit" game, we assumed that $t_{r}>0$. If $t_{r}=0$, in all equilibria of that game there is no tax collection from dishonest rich taxpayers. Hence, we can assume without loss of generality that there is no misreporting and, therefore, no audits.
} 


\subsubsection{Choosing regimes}

Naturally, the government will choose a tax law leading to the regime that generates the highest expected welfare. The following proposition completely characterizes the main result of this paper.

\section{Proposition 4}

- If $\theta<1$, there exists a value of the audit cost $\bar{c}^{n c} \in\left(0, c_{1}\right)$ such that $\mathbb{E} W^{P E}\left(\bar{c}^{n c}\right)=$ $\mathbb{E} W^{F E}\left(\bar{c}^{n c}\right)$. When $c<\bar{c}^{n c}, \mathbb{E} W^{P E}>\mathbb{E} W^{F E} ;$ otherwise $\mathbb{E} W^{P E}<\mathbb{E} W^{F E}$.

- If $\theta=1, \bar{c}^{n c}=c_{1}$. Thus, when $c<\bar{c}^{n c}, \mathbb{E} W^{P E}>\mathbb{E} W^{F E} ;$ otherwise $\mathbb{E} W^{P E}=\mathbb{E} W^{F E}$.

This proposition is most easily understood with reference to Figures 6 , which depict the maximum expected welfare levels attainable for each audit cost under each regime, i.e. it combines Figures 3 and 5 . The maximum feasible welfare level is represented by the upper envelope of $\mathbb{E} W^{P E}$ and $\mathbb{E} W^{F E}$.

$\theta<1 \quad \theta=1$

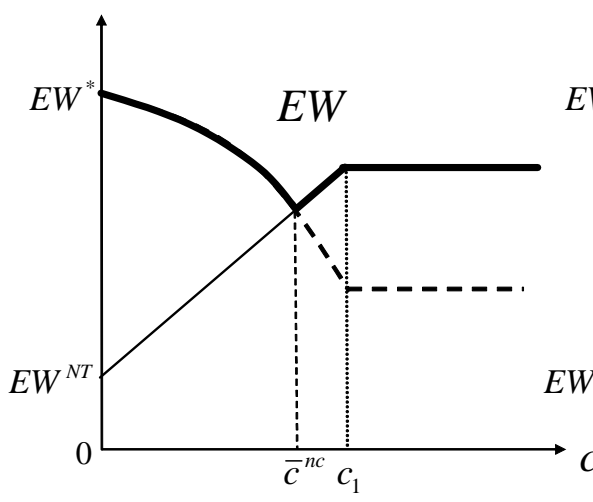

Figure 6(a)

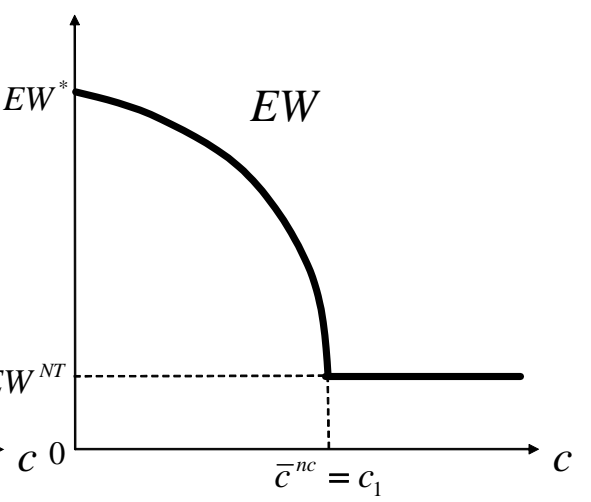

Figure 6(b)

Figures 6: Choice of regimes

When $\theta<1$ (i.e. when there are some honest rich taxpayers, no matter how few), since $\mathbb{E} W^{P E}$ (weakly) decreases with $c$, while $\mathbb{E} W^{F E}$ (weakly) grows with $c$, Figure 6(a) shows that there exists a positive audit $\operatorname{cost} \bar{c}^{n c}$ for which both welfare levels coincide. As is intuitive, for low audit cost the government chooses a tax law $\left(\widehat{t}_{r}^{P E}, \widehat{f}^{P E}\right)$ that gives way to regime $R^{P E}$, while for high audit costs it chooses a pair $\left(\widehat{t}_{r}^{F E}, \widehat{f}^{F E}\right)$ such that regime $R^{F E}$ obtains and the government never audits. Let us note that it is never optimal for the government to choose regime $R^{N T}$. Even when $\theta>\widehat{\theta}$ and for any audit cost $c>\widehat{c}$, the government can reach a higher welfare level by setting a positive tax level and low or no fines, so that regime $R^{F E}$ obtains. In other words, regime $R^{N T}$ is always dominated by regime $R^{F E}$.

Figure 6(a) depicts an interesting property of the upper envelope of $\mathbb{E} W^{P E}$ and $\mathbb{E} W^{F E}$ : $\mathbb{E} W^{P E}$ intersects $\mathbb{E} W^{F E}$ when the latter is increasing, as shown in the Appendix. This 
implies that expected welfare is nonmonotonic in audit costs. For some range of audit costs, the government strictly gains when audits become more costly, provided $\theta<1$. The intuition for this result is related to the absence of commitment to an audit probability. Under partial evasion, as $c$ grows the government lowers taxes to attenuate the increase in evasion. Still, welfare falls. As figure 6(a) shows, when $c \in\left(\bar{c}^{n c}, c_{1}\right)$ it may be the case that the government chooses to eliminate its own incentives to audit by setting no fine and selecting the maximum tax compatible with full evasion even when, under regime $R^{F E}$, that tax is strictly below the optimal full-information level. In a way, this means that the government chooses to commit not to audit not only by choosing not to fine evaders, but also by setting a low enough tax, as we explained above. An increase in $c$ lowers the cost the government has to pay to commit not to audit, i.e. it makes regime $R^{F E}$ compatible with a higher tax, and thereby raises expected welfare. ${ }^{24}$

As we mentioned in the Introduction, many articles explain why penalties for evaders are not optimally set at their maximal legal level. When $c \leq \bar{c}^{n c}$, this holds in our paper. But we are not aware of any other contribution where fines for evaders (or criminals in general) are optimally set at zero in the tax law, as happens here when $c \in\left(\bar{c}^{n c}, c_{1}\right)$. In the discussion below, we argue that this result is robust to changes in the model's assumptions.

When $\theta=1$, Figure $6(\mathrm{~b})$ shows that $\mathbb{E} W$ is weakly decreasing in $c$, just as under full commitment (see Section 2.1). The reason is simple: as all rich are dishonest, regime $R^{F E}$ yields expected welfare $\mathbb{E} W^{N T}$ for all $c$. Therefore, $\mathbb{E} W^{F E}$ is never strictly increasing, and thus the nonmonotonicity result in Figure 6(a) cannot obtain. Clearly, the presence of honest individuals substantially modifies the qualitative results of the model.

A numerical example We provide now a numerical example to illustrate the theoretical result of Figure 6. The utility function is

$$
u(q)=k \frac{1-\gamma}{\gamma}\left(\frac{q}{1-\gamma}\right)^{\gamma}
$$

with $k=10$ and $\gamma=0.5$. The remaining parameters are $y_{r}=100, y_{p}=50, \mu=0.75$ and $\theta=0.1$. The results are shown in Figures 7 below, where the values of some endogenous

\footnotetext{
${ }^{24}$ Note that the nonmonotonicity of expected welfare in the audit cost is possible because $\mathbb{E} W^{F E}>\mathbb{E} W^{P E}$ for $c>c_{1}$. For these audit costs, under both regimes, dishonest rich taxpayers misreport with probability one and all revenue comes from honest taxpayers. However, under full evasion, taxes are set at their fullinformation level, $t_{r}^{*}$ while $t_{r}$ is lower under partial evasion.
} 
variables of the model are plotted, as functions of the audit cost $c$.

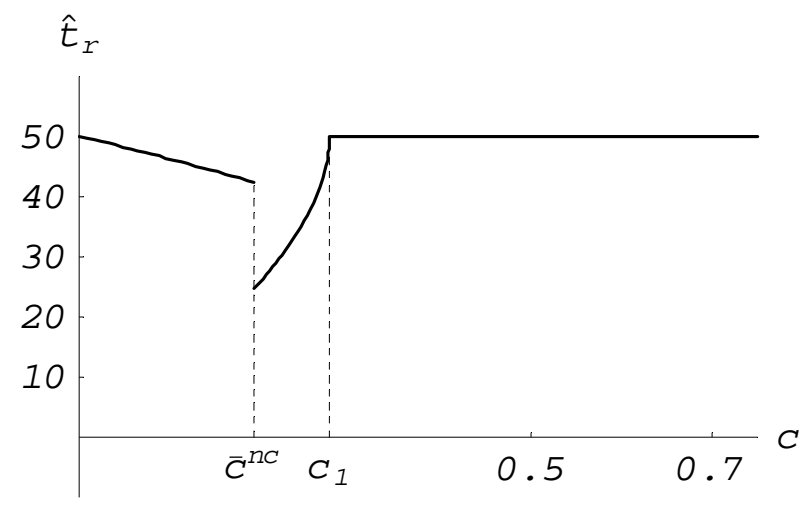

Figure $7(\mathrm{a})$

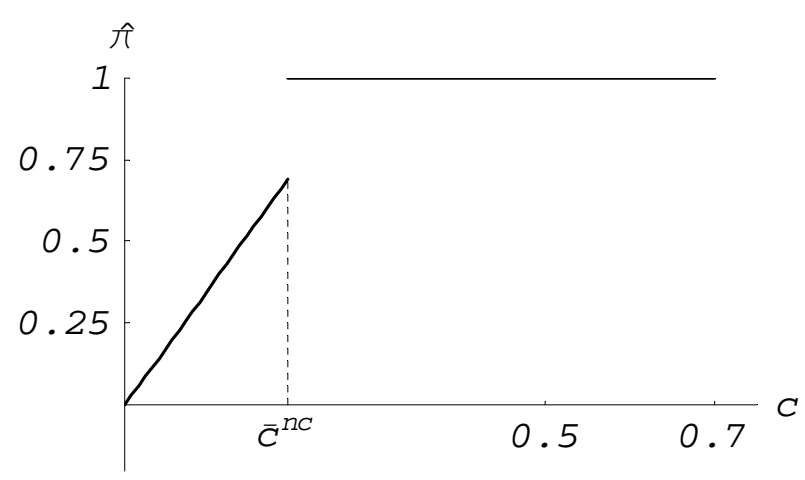

Figure 7(b)

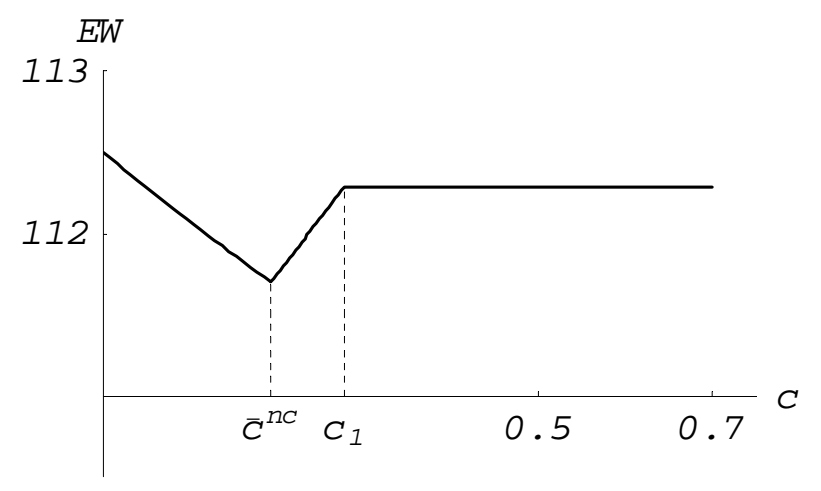

Figure $7(\mathrm{c})$

When $c<\bar{c}^{n c}=0.193$, the government chooses a tax law such that it effectively enforces it, at the second stage. The optimal tax $\widehat{t}_{r}^{P E}$ decreases with $c$ while individual evasion increases, yielding a decrease in expected welfare $\mathbb{E} W^{P E}$. Then, when $c \geq \bar{c}^{n c}$, the government changes and chooses a tax law that generates the other regime, with no enforcement. Interestingly, at $\bar{c}^{n c}$, the optimal tax jumps downwardly, from 42.31 to 24.61. Then $\widehat{t}_{r}^{P E}$ starts to increase, and it does so at an increasing rate. In spite of this jump, expected welfare is continuous and starts to increase, until $c=c_{1}=0.277$, where $\widehat{t}_{r}^{F E}=t_{r}^{*}=50$. Then, even if the audit cost increases, both $\widehat{t}_{r}^{F E}$ and $\mathbb{E} W^{F E}$ remain constant. Figure 7(c) depicts expected welfare for this example.

\section{More general assumptions and extensions of the model}

Here we analyze whether adopting more general assumptions or extending the model in several directions significantly alters the main results of the paper. 
More than two income levels In order to see whether assuming more than two income levels would change the results of the model, assume that individual incomes $y_{i}$ can adopt $n$ values $y_{1}, \ldots, y_{n}$, with $y_{1}<y_{2}<\ldots<y_{n}$. Let $0<p_{i}<1$ be the probability that any given taxpayer's income is $y_{i}, i=1, \ldots, n$. Again, assume that each taxpayer of type $y_{i}>y_{1}$ may be dishonest, with probability $\theta \in(0,1]$. Finally, denote by $t_{i}$ the tax due for a taxpayer with income $y_{i}>y_{1}$.

Although we cannot provide a complete characterization of the equilibrium of the reportaudit game, ${ }^{25}$ we know that a full-evasion regime will emerge for values of the audit cost above a threshold $\widetilde{c}$. The exact value of this threshold depends upon the tax law. In the full-evasion regime, all dishonest taxpayers report an income $y_{1}$, and thus, as no audits are performed, they pay no tax. Hence, expected welfare is

$$
\mathbb{E} W^{F E}=p_{1} u\left(y_{1}\right)+\sum_{y_{i}>y_{1}} p_{i}\left\{\theta u\left(y_{i}\right)+(1-\theta)\left[u\left(y_{i}-t_{i}\right)+t_{i}\right]\right\} .
$$

It can be easily shown that the optimal tax $\widehat{t}_{i}^{F E}$ is implicitly given by

$$
u^{\prime}\left(y_{i}-t_{i}\right)=1,
$$

yielding the optimal full-information taxes $t_{2}^{*}<\ldots<t_{i}^{*}<\ldots<t_{n}^{*}$.

Here, the same argument presented in Appendix 6.2 applies: for low values of the audit cost, the government cannot cause regime $R^{F E}$ to emerge with such a schedule of optimal taxes. Therefore, it is constrained to choose taxes $\widehat{t}_{i}^{F E}<t_{i}^{*}$. As $c$ increases, the government can increase $\widehat{t}_{i}^{F E}$ up to $t_{i}^{*}$, and then the optimal tax remains constant. So, as $\mathbb{E} W^{F E}$ is again concave in $t_{i}$, it weakly increases whenever $\widehat{t}_{i}^{F E}<t_{i}^{*}$. This leaves the door open for expected welfare to be nonmonotonic in the audit cost even with more than two income levels.

Taxation on the poor If the government also taxes the poor $^{26}$, the second-stage equilibrium probabilities become:

$$
\begin{aligned}
\widehat{\beta} & =\frac{u\left(y_{r}-t_{p}\right)-u\left(y_{r}-t_{r}\right)}{u\left(y_{r}-t_{p}\right)-u\left(y_{r}-t_{r}-f\right)} \\
\widehat{\pi} & =\frac{\mu c}{(1-\mu) \theta\left(t_{r}+f-t_{p}-c-\left[u\left(y_{r}-t_{p}\right)-u\left(y_{r}-t_{r}-f\right)\right]\right)}
\end{aligned}
$$

\footnotetext{
${ }^{25}$ More income levels imply more strategies for taxpayers, and thus more possibilities of misreporting, which yields more possible configurations of mixed-strategy equilibria. To the best of our knowledge, only Landsberger et al. (2000) have solved such a report-audit game. However, as they assume that audit costs depend on individual incomes, the enforcer does not know, when it chooses whether to audit a report, the cost it will finally bear. Thus, when audits are indeed performed, their equilibrium is different from ours. In their model, there always exists a non-audit regime, but, since it is not relevant to the main point of their paper, they assume it away.

${ }^{26}$ Again, distinguishing between honest and dishonest poor taxpayers is irrelevant because, even for dishonest poor taxpayers misreporting is a dominated strategy.
} 
where $t_{p}$ is the tax owed by poor individuals. This implies that the threshold $\widetilde{c}$ becomes

$$
\widetilde{c}=\frac{(1-\mu) \theta}{(1-\mu) \theta+\mu}\left(t_{r}-t_{p}+f-\left[u\left(y_{r}-t_{p}\right)-u\left(y_{r}-t_{r}-f\right)\right]\right) .
$$

Moving back to the first stage, the optimal tax laws are obviously different than the ones obtained in the previous sections. Nevertheless, the qualitative results hold. ${ }^{27}$ In particular, when the government wishes to generate regime $R^{F E}$, two cases emerge. When the audit cost is relatively low, the optimal tax law verifies $\widehat{t}_{r}^{F E}<t_{r}^{*}, \widehat{t}_{p}^{F E}>t_{p}^{*}$,

$$
\widehat{t}_{r}^{F E}-\widehat{t}_{p}^{F E}-\left[u\left(y_{r}-\widehat{t}_{p}^{F E}\right)-u\left(y_{r}-\widehat{t}_{r}^{F E}\right)\right]=\left(1+\frac{\mu}{(1-\mu) \theta}\right) c, \text { and } \widehat{f}^{F E}=0 .
$$

On the other hand, when the audit cost is relatively high, $\widehat{t}_{r}^{F E}=t_{r}^{*}, \widehat{f}^{F E}>0$ and $\widehat{t}_{p}^{F E}>t_{p}^{*}$. Comparative statics show that, in the first case, expected welfare increases with respect to the audit cost whereas, in the second case, it does not depend upon this parameter. Therefore, under some parameter conditions, we obtain again that the government's optimal response to tax evasion is not to fine evaders and that expected welfare can be nonmonotonic in the audit cost.

The use of a non-linear utility function We could have adopted a more standard utility function, $u\left(q_{i}\right)+v(g)$. In this case, the optimal full-information tax $t_{r}^{*}$ is implicitly given by the following first-order condition

$$
u^{\prime}\left(y_{i}-t_{r}^{*}\right)=v^{\prime}\left((1-\mu) t_{r}^{*}\right)
$$

and verifies the second-order condition for a maximum.

As we mentioned above, the use of a concave function $v($ ) substantially modifies the equilibrium of the report-audit game, especially the characterization of the partial-evasion regime. Nevertheless, a full-evasion regime obtains. ${ }^{28}$ In this regime, expected welfare is

$$
\mathbb{E} W^{F E}=\mu u\left(y_{p}\right)+(1-\mu)\left[\theta u\left(y_{r}\right)+(1-\theta) u\left(y_{r}-t_{r}\right)\right]+v\left((1-\mu)(1-\theta) t_{r}\right)
$$

It is straightforward to show that the optimal tax $\widehat{t}_{r}^{F E}$ is higher than the optimal fullinformation tax $t_{r}^{*}$. Therefore, the argument presented in Appendix 6.2 applies here as well. Hence, the linearity of the utility function in the public good is not crucial for our main result.

\footnotetext{
${ }^{27}$ The proofs of these results are available upon request.

${ }^{28}$ It may seem that, with a concave utility function, not auditing cannot happen in equilibrium: the infinite value of the marginal utility of the public good could imply that auditing someone is always optimal. However, as some honest taxpayers comply with the tax law, the provision of public goods is always strictly positive. Thus $v^{\prime}<<\infty$ and so regime $R^{F E}$ can emerge.
} 
The model with a tax administration We have just shown that, in the first stage of the model, the government uses the levels of the tax and the fine as commitment devices. But they are not the only available devices. Melumad and Mookherjee (1989) show that the government can indirectly commit to enforcing the tax law by delegating this task to an independent and (net) revenue-maximizing tax administration. This organizational separation is by now commonly accepted in the literature of optimal tax-enforcement policies [see, among others, Cremer et al. (1990) and Sanchez and Sobel (1993)]. What happens in our model if we assume that the government first sets the tax law (without committing to the audit policy) and then, as in Graetz et al. (1986), a (net) revenue-maximizing tax administration collects taxes and enforces the tax law, at the second stage? Is there room for the use of taxes and fines as commitment devices?

At the second stage, as the tax administration decides about enforcement to maximize expected net tax revenue, the equilibrium probability of misreport becomes

$$
\widehat{\pi}=\frac{\mu c}{(1-\mu) \theta\left[t_{r}+f-c\right]} .
$$

This probability is only determined by monetary benefits and costs of auditing. Now the value of the threshold $\widetilde{c}$ characterized in Proposition 1 changes. Moving back to the first stage, the fact that $\widehat{\pi}$ does not include any change in utility implies that, when the government wishes regime $R^{P E}$ to emerge, it is optimal to fix the penalty at its maximal legal level $y_{r}-t_{r}$, to attenuate tax evasion, by reducing its stake. This has two consequences. First, the threshold $\widetilde{c}$ is fixed at its highest level. Therefore, the last constraint in the analog of problem $\mathcal{P}^{P E}$ for this environment, is automatically verified and can be done away with. Second, penalizing evaders at the maximum also (indirectly) fixes the level of individual and aggregate evasion at the equilibrium of the second stage, as in our basic model. The optimal tax $\widehat{t}_{r}^{P E}$ also decreases with $c$. When the government wishes to generate regime $R^{F E}$, nothing changes qualitatively. Therefore, even when there is a tax administration, the main result regarding the possibility of not fining evaders and the nonmonotonicity of the expected welfare when the government chooses between regimes remains valid. ${ }^{29}$ The main difference with the previous section is the following: we cannot exclude the case where, in the analog of Figure 6(a), the profile of $\mathbb{E} W^{P E}$ intersects $\mathbb{E} W^{F E}$ when the latter is flat.

Costly taxation and imperfect audits Finally, we have assumed that tax collection is costless, both for taxpayers and for the tax administration, and that audits are perfect. If this were not the case, Regime $R^{F E}$ would emerge for lower values of the audit cost. Therefore, our results would be reinforced.

\footnotetext{
${ }^{29}$ There is one more possible case: that of a revenue-maximizing government. Clearly, the results will differ. For example, in the partial-evasion regime, the government will try to minimize penalties, but for a different reason: to relax the limited-liability constraint. However, assuming that revenue maximization is the unique government objective seems rather extreme, so we prefer not to fully examine this case.
} 


\section{Conclusion}

This paper studies optimal taxes and fines in a two-period model under no commitment. In the first period, the government designs the tax law, which comprises taxes and fines to impose to evaders. In the second period, evasion and costly enforcement take place. Taxpayers report their income to the government. Next, the government decides whether to audit each report or not. If a misreport is detected, evaders are penalized; otherwise, taxpayers pay the tax that corresponds to their reported income.

The main results of the paper are the following. First, the characterization of the optimal tax law crucially depends upon the existence of honest taxpayers. Second, in the partialevasion regime, the tax monotonically decreases with the audit cost whereas in the fullevasion regime the tax weakly increases with the audit cost. Third, for some parameter values, it may be optimal for the government to impose no fines for evaders as a way to commit not to audit. Fourth, we show that as long as some taxpayers are honest, expected social welfare is nonmonotonic in the audit cost. Finally, we extend the model in several directions, confirming its qualitative results.

Clearly, this model is a first step in the analysis of optimal tax-enforcement policies under no commitment. Relaxing some of our assumptions, e.g. abandoning the exogeneity of honesty, is a promising venue for future research. Finally, although the model is quite stylized, it may have some distinctive implications that deserve empirical testing. 


\section{Appendix}

\subsection{Proof of Proposition 1}

The derivation of the unique, pure-strategy PBE that obtains when $c>\widetilde{c}$ is straightforward.

When $c<\widetilde{c}$, it is not possible that the government audits with probability zero (one) at an equilibrium. Dishonest rich taxpayers would then misreport with probability one (respectively, zero), which would render the government's pure strategy suboptimal. Then the PBE has to be in mixed strategies, so the government has to be indifferent between auditing and not auditing a low-income report. If dishonest rich taxpayers misreport with probability $\pi$, when the government receives a low-income report the updated probability it attaches to the taxpayer being poor is $\mu / \nu$, where $\nu=\mu+(1-\mu) \theta \pi$. For the government, then, the expected welfare of auditing such a report is

$$
\frac{(1-\mu) \theta \pi}{\nu}\left[u\left(y_{r}-t_{r}-f\right)+t_{r}+f\right]+\frac{\mu}{\nu} u\left(y_{p}\right)-c
$$

whereas the expected welfare of not auditing is

$$
\frac{(1-\mu) \theta \pi}{\nu} u\left(y_{r}\right)+\frac{\mu}{\nu} u\left(y_{p}\right)
$$

Equating these two expressions and solving yields $\widehat{\pi}$ in (2).

If $c<\widetilde{c}, \widehat{\pi} \in(0,1)$. Thus, dishonest rich taxpayers have to be indifferent between reporting truthfully and misreporting. Given that the government audits low-income reports with probability $\beta$, if a dishonest rich taxpayer misreports her expected utility is

$$
\beta u\left(y_{r}-t_{r}-f\right)+(1-\beta) u\left(y_{r}\right) .
$$

Equating this expression to the utility reached with a truthful report, $u\left(y_{r}-t_{r}\right)$ and solving, the value of $\widehat{\beta}$ in (1) obtains.

When $c=\widetilde{c}, \widehat{\pi}=1$. Therefore, any $\beta$ could be an equilibrium probability of auditing as long as dishonest rich taxpayers find it optimal to misreport. Then, there is a continuum of equilibria, with $\beta \in[0, \widehat{\beta}]$

\subsection{Proof of Proposition 2}

We present an heuristic proof, based on geometric arguments. Recall that feasible tax laws should verify $t_{r}+f \leq y_{r}$. Let $\Psi=\left\{\left(t_{r}, f\right): t_{r}, f \geq 0, t_{r}+f=t_{r}^{*}\right\}$. $\Psi$ is a line with slope $(-1)$ in the $\left(t_{r}, f\right)$ plane. For any given value of the audit cost $c$, the locus of tax laws that separate regime $R^{F E}$ from regime $R^{P E}$ is implicitly given by

$$
u\left(y_{r}\right)+\frac{[(1-\mu) \theta+\mu] c}{(1-\mu) \theta}=t_{r}+f+u\left(y_{r}-t_{r}-f\right) .
$$


Note that (5) only depends on $t_{r}+f$. Then, it also defines a line $\Gamma$ in the plane $\left(t_{r}, f\right)$, with slope $(-1)$. This line shifts farther to the right when $c$ increases. As the government wishes to stay within regime $R^{F E}$, chosen tax laws have to lie below $\Gamma$.

When

$$
c \geq c_{1}=\frac{(1-\mu) \theta}{(1-\mu) \theta+\mu}\left(t_{r}^{*}-\left[u\left(y_{r}\right)-u\left(y_{r}-t_{r}^{*}\right)\right]\right)
$$

$\Gamma$ lies above $\Psi$. Therefore, as the expression to maximize in (3) is -but for a constant factor that does not affect the solution- the same as under full information, ${ }^{30} \widehat{t}_{r}^{F E}=t_{r}^{*}$ and $\widehat{f}^{F E} \in[0, \bar{f}]$, where $\bar{f}$ is implicitly given by

$$
u\left(y_{r}\right)+\frac{[(1-\mu) \theta+\mu] c}{(1-\mu) \theta}=t_{r}^{*}+\bar{f}+u\left(y_{r}-t_{r}^{*}-\bar{f}\right) .
$$

In fact, $\bar{f}$ is the highest fine compatible with full evasion when $t_{r}=t_{r}^{*}$. By construction, if $\Gamma \subset \Omega, \bar{f} \leq y_{r}-t_{r}^{*}$. Therefore, when $c \geq c_{1}, \mathbb{E} W^{F E}$ is constant in $c$.

On the other hand, when $c<c_{1}$, $\Gamma$ lies below $\Psi$ and thus $t_{r}^{*}$ is no longer attainable. When this is the case, expected welfare $\mathbb{E} W^{F E}$ increases with the tax $t_{r}$. Therefore, the optimal $\operatorname{tax} \widehat{t}_{r}^{F E}<t_{r}^{*}$ is implicitly given by

$$
u\left(y_{r}\right)+\frac{[(1-\mu) \theta+\mu] c}{(1-\mu) \theta}=\widehat{t}_{r}^{F E}+u\left(y_{r}-\widehat{t}_{r}^{F E}\right),
$$

where $\widehat{t}_{r}^{F E}$ is the highest tax compatible with regime $R^{F E}$ when $\widehat{f}^{F E}=0$. Clearly, $\lim _{c \rightarrow 0}$ $\widehat{t}_{r}^{F E}=0$. Applying the Implicit Function Theorem to (6), we obtain

$$
\frac{\partial \widehat{t}_{r}^{F E}}{\partial c}=\frac{[(1-\mu) \theta+\mu]}{(1-\mu) \theta} \frac{1}{1-u^{\prime}\left(y_{r}-\widehat{t}_{r}^{F E}\right)}>0
$$

where the sign of the inequality follows from the fact that $u($.$) is concave and \widehat{t}_{r}^{F E}<t_{r}^{*}$. Moreover,

$$
\frac{\partial^{2} \widehat{t}_{r}^{F E}}{\partial c^{2}}=\frac{-u^{\prime \prime}\left(y_{r}-\widehat{t}_{r}^{F E}\right)}{1-u^{\prime}\left(y_{r}-\widehat{t}_{r}^{F E}\right)}\left(\frac{\partial \widehat{t}_{r}^{F E}}{\partial c}\right)^{2}>0 .
$$

Thus, when $c<c_{1}, \lim _{c \rightarrow 0} \mathbb{E} W^{F E}=\mathbb{E} W^{N T}$,

$$
\frac{\partial \mathbb{E} W^{F E}}{\partial c}=(1-\mu)(1-\theta)\left[1-u^{\prime}\left(y_{r}-\widehat{t}_{r}^{F E}\right)\right] \frac{\partial \widehat{t}_{r}^{F E}}{\partial c}>0
$$

and

$$
\frac{\partial^{2} \mathbb{E} W^{F E}}{\partial c^{2}}=0
$$

So $\mathbb{E} W^{F E}$ increases linearly with $c$

\footnotetext{
${ }^{30}$ Since this expression is concave in its arguments, the second-order conditions hold.
} 


\subsection{Proof of Proposition 3}

$\underline{\text { First-order conditions of problem } \mathcal{P}^{P E}}$

The optimal tax law under regime $R^{P E}$ solves the following problem, denoted by $\mathcal{P}^{P E}$.

$$
\mathcal{P}^{P E}\left\{\begin{array}{l}
\underset{t_{r}, f}{\operatorname{Max}} \mu u\left(y_{p}\right)+(1-\mu) u\left(y_{r}-t_{r}\right)+(1-\mu)(1-\theta \widehat{\pi}) t_{r} \\
\text { subject to } \\
t_{r}+f \leq y_{r} \quad(\lambda) \\
\widehat{\pi}=\frac{\mu c}{(1-\mu) \theta\left(t_{r}+f-c-\left[u\left(y_{r}\right)-u\left(y_{r}-t_{r}-f\right)\right]\right)} \\
c \leq \frac{(1-\mu) \theta}{(1-\mu) \theta+\mu}\left(t_{r}+f-\left[u\left(y_{r}\right)-u\left(y_{r}-t_{r}-f\right)\right]\right)
\end{array}\right.
$$

where $\lambda$ is the multiplier associated with the ex-post limited-liability constraint. If we neglect for the moment the last constraint, the Lagrangean of this problem is

$$
\mathcal{L}=\mu u\left(y_{p}\right)+(1-\mu) u\left(y_{r}-t_{r}\right)+(1-\mu)(1-\theta \widehat{\pi}) t_{r}-\lambda\left(t_{r}+f-y_{r}\right) .
$$

The first-order conditions of the relaxed problem are as follows:

$$
\left\{\begin{array}{l}
\frac{\partial \mathcal{L}}{\partial t_{r}}=-(1-\mu) u^{\prime}\left(y_{r}-\widehat{t}_{r}^{P E}\right)+(1-\mu)\left[1-\theta \widehat{\pi}-\theta \widehat{t}_{r}^{P E} \frac{\partial \widehat{\pi}}{\partial t_{r}}\right]-\widehat{\lambda}=0 \\
\frac{\partial \mathcal{L}}{\partial f}=-(1-\mu) \theta \widehat{t}_{r}^{P E} \frac{\partial \widehat{\pi}}{\partial f}-\widehat{\lambda}=0 \\
\widehat{\lambda}\left(\widehat{t}_{r}^{P E}+\widehat{f}^{P E}-y_{r}\right)=0 \quad \widehat{\lambda} \geq 0
\end{array}\right.
$$

From (FOC2) we obtain

$$
\widehat{\lambda}=-(1-\mu) \theta \widehat{t}_{r}^{P E} \frac{\partial \widehat{\pi}}{\partial f}
$$

where

$$
\frac{\partial \widehat{\pi}}{\partial f}=-\frac{\mu c\left[1-u^{\prime}\left(y_{r}-t_{r}-f\right)\right]}{(1-\mu) \theta\left(t_{r}+f-c-\left[u\left(y_{r}\right)-u\left(y_{r}-t_{r}-f\right)\right]\right)^{2}} .
$$

As we have assumed that the "report-audit" game is played provided $t_{r}>0, \widehat{\lambda} \geq 0$ implies that $u^{\prime}\left(y_{r}-\widehat{t}_{r}^{P E}-\widehat{f}^{P E}\right) \leq 1$. By the concavity of the utility function, this in turn implies that $\widehat{t}_{r}^{P E}+\widehat{f}^{P E} \leq t_{r}^{*}$. As $t_{r}^{*}<y_{r}$, the ex-post limited-liability constraint does not bind, so $\widehat{\lambda}=0$. Hence $u^{\prime}\left(y_{r}-\widehat{t}_{r}^{P E}-\widehat{f}^{P E}\right)=1, \partial \widehat{\pi} / \partial f=0$ and finally $\widehat{t}_{r}^{P E}+\widehat{f}^{P E}=t_{r}^{*}$. The precise value of $\widehat{t}_{r}^{P E}$ is obtained by replacing $\widehat{\lambda}=0$ in (FOC1), observing that $\partial \widehat{\pi} / \partial t_{r}=\partial \widehat{\pi} / \partial f$ and rearranging. The reduced form of the first-order condition that defines the optimal tax $\widehat{t}_{r}^{P E}$ is

$$
u^{\prime}\left(y_{r}-\widehat{t}_{r}^{P E}\right)=1-\theta \widehat{\pi}<1 .
$$


Again, by the concavity of the utility function, $\widehat{t}_{r}^{P E} \leq t_{r}^{*}$.

So far we have ignored the last constraint in problem $\mathcal{P}^{P E}$. Note that if $c<c_{1}=$ $\frac{(1-\mu) \theta}{(1-\mu) \theta+\mu}\left(t_{r}^{*}-\left[u\left(y_{r}\right)-u\left(y_{r}-t_{r}^{*}\right)\right]\right)$, this inequality holds in the solution to the relaxed problem. Hence, the constraint is not binding and we have characterized the solution to $\mathcal{P}^{P E}$.

When $c \geq c_{1}$, for $\left(t_{r}, f\right)$ to be compatible with regime $R^{P E}$ we must have $t_{r}+f>t_{r}^{*}$. This implies that $u^{\prime}\left(y_{r}-t_{r}-f\right)>1$. Thus, $\frac{\partial \widehat{\pi}}{\partial f}>0$, and the government's objective function is decreasing in $f$. Then, the government chooses $\widehat{t}_{r}^{P E}+\widehat{f}^{P E}$ such that $c=\widetilde{c}$, thereby generating the case where $\widehat{\pi}=1$, and it is indifferent between auditing low-income reports and not doing so. The corresponding tax rate $\widehat{t}_{r}^{P E}=t_{r}^{\prime}$ is such that $u^{\prime}\left(y_{r}-t_{r}^{\prime}\right)=1-\theta$.

\section{Second-order conditions of the relaxed problem}

Let us denote by $\mathbf{s}$ the tax law $\left(t_{r}^{P E}, f^{P E}\right)$. As the objective function (4) is not globally concave, we have to check if the Hessian matrix of the function

$$
\mathcal{L}(\mathbf{s}, \lambda)=\mu u\left(y_{p}\right)+(1-\mu) u\left(y_{r}-t_{r}\right)+(1-\mu)(1-\theta \widehat{\pi}) t_{r}-\lambda\left(t_{r}+f-y_{r}\right)
$$

evaluated at $(\widehat{\mathbf{s}}, \widehat{\lambda})$ is negative semidefinite. That matrix, evaluated at $(\widehat{\mathbf{s}}, \widehat{\lambda})$, is

$$
\nabla_{s s}^{2} \mathcal{L}(\widehat{\mathbf{s}}, \widehat{\lambda})=\left[\begin{array}{ll}
\frac{\partial^{2} \mathcal{L}(\widehat{\mathbf{s}}, \widehat{\lambda})}{\partial t_{r}^{2}} & \frac{\partial^{2} \mathcal{L}(\widehat{\mathbf{s}}, \widehat{\lambda})}{\partial f \partial t_{r}} \\
\frac{\partial^{2} \mathcal{L}(\widehat{\mathbf{s}}, \widehat{\lambda})}{\partial t_{r} \partial f} & \frac{\partial^{2} \mathcal{L}(\widehat{\mathbf{s}}, \widehat{\lambda})}{\partial f^{2}}
\end{array}\right]
$$

where

$$
\begin{aligned}
& \frac{\partial^{2} \mathcal{L}(\widehat{\mathbf{s}}, \widehat{\boldsymbol{\lambda}})}{\partial t_{r}^{2}}=(1-\mu) u^{\prime \prime}\left(y_{r}-\widehat{t}_{r}^{P E}\right)-(1-\mu) \theta \widehat{t}_{r}^{P E} \frac{\partial^{2} \widehat{\pi}}{\partial t_{r}^{2}} \\
& \frac{\partial^{2} \mathcal{L}(\widehat{\mathbf{s}}, \widehat{\lambda})}{\partial f \partial t_{r}}=\frac{\partial^{2} \mathcal{L}(\widehat{\mathbf{s}}, \widehat{\lambda})}{\partial t_{r} \partial f}=-(1-\mu) \theta \widehat{t}_{r}^{P E} \frac{\partial^{2} \widehat{\pi}}{\partial t_{r} \partial f} \\
& \frac{\partial^{2} \mathcal{L}(\widehat{\mathbf{s}}, \widehat{\lambda})}{\partial f^{2}}=-(1-\mu) \widehat{\theta t_{r}^{P E}} \frac{\partial^{2} \widehat{\pi}}{\partial f^{2}}
\end{aligned}
$$

It is straightforward to show that

$$
\frac{\partial^{2} \widehat{\pi}}{\partial t_{r}^{2}}=\frac{\partial^{2} \widehat{\pi}}{\partial f \partial t_{r}}=\frac{\partial^{2} \widehat{\pi}}{\partial f^{2}}=-\frac{\left.\mu c u^{\prime \prime}\left(y_{r}-t_{r}-f\right)\right)}{(1-\mu) \theta\left(t_{r}+f-c-\left[u\left(y_{r}\right)-u\left(y_{r}-t_{r}-f\right)\right]\right)^{2}}>0 .
$$

Hence,

$$
\left\{\begin{array}{l}
\frac{\partial^{2} \mathcal{L}(\widehat{\mathbf{s}}, \widehat{\lambda})}{\partial t_{r}^{2}}=(1-\mu) u^{\prime \prime}\left(y_{r}-\widehat{t}_{r}^{P E}\right)-(1-\mu) \theta \widehat{t}_{r}^{P E} \frac{\partial^{2} \widehat{t}}{\partial t_{r}^{2}}<0 \\
\frac{\partial^{2} \mathcal{L}(\widehat{\mathbf{s}}, \widehat{\lambda})}{\partial t_{r}^{2}} \frac{\partial^{2} \mathcal{L}(\widehat{\mathbf{s}}, \widehat{\lambda})}{\partial f^{2}}-\left(\frac{\partial^{2} \mathcal{L}(\widehat{\mathbf{s}}, \widehat{\lambda})}{\partial f \partial t}\right)^{2}=-(1-\mu)^{2} \theta \widehat{t}_{r}^{P E} \frac{\partial^{2} \widehat{t}}{\partial t_{r}^{2}} u^{\prime \prime}\left(y_{r}-\widehat{t}_{r}^{P E}\right)>0
\end{array}\right.
$$

These signs ensure that the Hessian matrix of $\mathcal{L}(\mathbf{s}, \lambda)$, evaluated at $(\widehat{\mathbf{s}}, \widehat{\lambda})$, is negative semidefinite. Thus, the first-order conditions of the relaxed problem verify the second-order conditions for a maximum, and they are also sufficient to characterize the optimal schedule $\left(\widehat{t}_{r}^{P E}, \widehat{f}^{P E}\right)$. 


\section{Comparative statics}

By the Maximum Theorem [Berge (1963)], the optimal tax $\widehat{t}_{r}^{P E}$ is a continuous function of the audit cost $c$. In order to completely characterize the optimal schedule $\left(\widehat{t}_{r}^{P E}, \widehat{f}^{P E}\right)$, let's compute $\frac{\partial \hat{t}_{r}^{P E}}{\partial c}$ and $\frac{\partial \widehat{\pi}}{\partial c}$. Applying the Implicit Function Theorem, we can show that

$$
\frac{\partial \widehat{t}_{r}^{P E}}{\partial c}=\frac{\mu}{(1-\mu) u^{\prime \prime}\left(y_{r}-\widehat{t}_{r}^{P E}\right)} \frac{t_{r}^{*}-\left[u\left(y_{r}\right)-u\left(y_{r}-t_{r}^{*}\right)\right]}{\left(t_{r}^{*}-c-\left[u\left(y_{r}\right)-u\left(y_{r}-t_{r}^{*}\right)\right]\right)^{2}}<0
$$

and

$$
\frac{\partial \widehat{\pi}}{\partial c}=\mu \frac{t_{r}^{*}-\left[u\left(y_{r}\right)-u\left(y_{r}-t_{r}^{*}\right)\right]}{\left(t_{r}^{*}-c-\left[u\left(y_{r}\right)-u\left(y_{r}-t_{r}^{*}\right)\right]\right)^{2}}>0
$$

because, by concavity, $u\left(y_{r}\right)<u\left(y_{r}-t_{r}^{*}\right)+\underbrace{u^{\prime}\left(y_{r}-t_{r}^{*}\right)}_{=1} t_{r}^{*}$.

\section{Domain of positive taxation}

We have described completely case A in Proposition 3. There is another possibility: if $\theta$ is large enough, as $c_{1}$ grows with $\theta$, the optimal tax may go to zero. We examine this situation here.

From (7), we can find the value $\widehat{c}$ that generates the limit case $\widehat{t}_{r}^{P E} \rightarrow 0$. This value is implicitly characterized by the following expression

$$
u^{\prime}\left(y_{r}\right)=1-\frac{\mu \widehat{c}}{(1-\mu)\left(t_{r}^{*}-\widehat{c}-\left[u\left(y_{r}\right)-u\left(y_{r}-t_{r}^{*}\right)\right]\right)} .
$$

After some manipulations, we obtain

$$
\widehat{c}=\frac{\left(1-u^{\prime}\left(y_{r}\right)\right)(1-\mu)\left(t_{r}^{*}-\left[u\left(y_{r}\right)-u\left(y_{r}-t_{r}^{*}\right)\right]\right)}{1-(1-\mu) u^{\prime}\left(y_{r}\right)} .
$$

It will be useful to compare $\widehat{c}$ to $c_{1}$. As

$$
\widehat{c}-c_{1}=\frac{\mu(1-\mu)\left(t_{r}^{*}-\left[u\left(y_{r}\right)-u\left(y_{r}-t_{r}^{*}\right)\right]\right)\left[1-u^{\prime}\left(y_{r}\right)-\theta\right]}{\left[1-(1-\mu) u^{\prime}\left(y_{r}\right)\right][(1-\mu) \theta+\mu]},
$$

$\widehat{c} \gtreqless c_{1}$ if and only if $\theta \gtreqless 1-u^{\prime}\left(y_{r}\right) \equiv \widehat{\theta}$. This completes the characterization of the tax profile for case B in Proposition 3 


\subsection{Proof of Proposition 4}

Assume that $\theta<\widehat{\theta}$. Let's study the behavior of the function

$$
\Delta(c) \equiv \mathbb{E} W^{P E}(c)-\mathbb{E} W^{F E}(c) .
$$

We know that

$$
\begin{gathered}
\lim _{c \rightarrow 0} \Delta(c)=\mathbb{E} W^{*}-\mathbb{E} W^{N T}>0 \\
\frac{\partial \Delta(c)}{\partial c}=\frac{\partial \mathbb{E} W^{P E}(c)}{\partial c}-\frac{\partial \mathbb{E} W^{F E}(c)}{\partial c}<0 \quad \text { for } c \in\left(0, c_{1}\right), \\
\lim _{c \rightarrow c_{1}} \Delta(c)=\lim _{c \rightarrow c_{1}} \mathbb{E}^{P E}-\lim _{c \rightarrow c_{1}} \mathbb{E} W^{F E}
\end{gathered}
$$

where

$$
\begin{aligned}
\lim _{c \rightarrow c_{1}} \mathbb{E} W^{P E} & =\mu u\left(y_{p}\right)+(1-\mu) u\left(y_{r}-\lim _{c \rightarrow c_{1}} \widehat{t}_{r}^{P E}\right)+(1-\mu)\left(1-\theta \lim _{c \rightarrow c_{1}} \widehat{\pi}\right) \lim _{c \rightarrow c_{1}} \widehat{t}_{r}^{P E} \\
& =\mu u\left(y_{p}\right)+(1-\mu) \underbrace{\theta u\left(y_{r}-\lim _{c \rightarrow c_{1}} \widehat{t}_{r}^{P E}\right)}_{<u\left(y_{r}\right)}+(1-\mu)(1-\theta) \underbrace{\left(u\left(y_{r}-\lim _{c \rightarrow c_{1}} \widehat{t}_{r}^{P E}\right)+\lim _{c \rightarrow c_{1}} \widehat{t}_{r}^{P E}\right)}_{<u\left(y_{r}-t_{r}^{*}\right)+t_{r}^{*}} .
\end{aligned}
$$

Thus, $\lim _{c \rightarrow c_{1}} \Delta(c)<0$. Hence, as the function $\Delta(c)$ is continuous and decreasing on $\left(0, c_{1}\right]$ and $\lim _{c \rightarrow 0} \Delta(c)>0>\lim _{c \rightarrow c_{1}} \Delta(c)$, there exists a unique critical value $\bar{c}^{n c}$ such that $\Delta\left(\bar{c}^{n c}\right)=0$ (Bolzano's Theorem). When $c<(>) \bar{c}^{n c}, \mathbb{E} W^{P E}(c)>(<) \mathbb{E} W^{F E}(c)$.

When $\widehat{\theta} \leq \theta<1$, the proof is the same but easier, because $\lim _{c \rightarrow c_{1}} \mathbb{E} W^{P E}=\mathbb{E} W^{N T}<$ $\lim _{c \rightarrow c_{1}} \mathbb{E} W^{F E}$.

When $\theta=1, \mathbb{E} W^{F E}(c)=\mathbb{E} W^{N T}$ and thus $\bar{c}^{n c}=c_{1}$

\section{References}

[1] Allingham, M. and A. Sandmo (1972) "Income Tax Evasion: A Theoretical Analysis", Journal of Public Economics, 1, 323-338.

[2] Anderson, J. and L. Carasciuc (2004) "Tax Evasion in a Transition Economy: Theory and Empirical Evidence from the Former Soviet Union Republic of Moldova", in A. Tavidze (ed.) Progress in Economics Research Vol. 8, Nova Science, Hauppauge, New York.

[3] Andreoni, J., B. Erard and J. Feinstein (1998) "Tax Compliance", Journal of Economic Literature, 36, 818-860. 
[4] Baldry, J. (1986) "Tax evasion is not a gamble: A report on two experiments", Economic Letters, 22, 333-335.

[5] Benjamini, Y. and S. Maital (1985) "Optimal tax evasion and optimal tax evasion policy", in W. Gartner and A. Wenig (eds.) The economics of the shadow economy, Springer-Verlag, Berlin.

[6] Berge, C. (1963) Topological Spaces, New York, Macmillan.

[7] Bloch, F. and U. Zenginobuz (2006) "Tiebout equilibria in local public good economies with spillovers", Journal of Public Economics, 90, 1745-1763.

[8] Boadway, R. and M. Keen (1998) "Evasion and Time Consistency in the Taxation of Capital Income", International Economic Review, 39, 461-476.

[9] Boadway, R., N. Marceau and M. Marchand (1996) "Time-consistent criminal sanctions", Public Finance/Finances Publiques, 51, 149-165.

[10] Border, K. and J. Sobel (1987) "Samurai Accountant: A Theory of Auditing and Plunder", Review of Economic Studies, 54, 525-540.

[11] Chander, P. and L. Wilde (1998) "A General Characterization of Optimal Income Tax Enforcement", Review of Economic Studies, 65, 165-183.

[12] Cowell, F. (1985) "The Economic Analysis of Tax Evasion", Bulletin of Economic Research, 37, 163-193.

[13] Cremer, H. and F. Gahvari (1994) "Tax Evasion, Concealment and the Optimal Linear Income Tax", Scandinavian Journal of Economics, 96, 219-239.

[14] Cremer, H. and F. Gahvari (1995) "Tax evasion and the optimum general income tax", Journal of Public Economics, 60, 235-249.

[15] Cremer, H., M. Marchand and P. Pestieau (1990) "Evading, Auditing and Taxing The Equity-Efficiency Tradeoff", Journal of Public Economics, 43, 67-92.

[16] Emons, W. (2004) "Subgame Perfect Punishment for Repeat Offenders", Economic Inquiry, 42 , 496-502.

[17] Emons, W. (2006) "Optimal Punishment for Repeat Offenders when the Government Can and Cannot Commit to Sanctions", in M. Boyer, Y. Hiriart, D. Martimort (eds.) Frontiers in the Economics of Environmental Regulation and Liability, Ashgate Publishers, 155-171.

[18] Erard, B. and J. Feinstein (1994) "Honesty and evasion in the tax compliance game," RAND Journal of Economics, 25, 1-19. 
[19] Garoupa, N. (1997) "The theory of optimal law enforcement", Journal of Economic Surveys, 11, 267-295.

[20] Gordon, J. (1989) "Individual morality and reputation costs as deterrents to tax evasion", European Economic Review, 33, 797-805.

[21] Graetz, M., J. Reinganum and L. Wilde (1986) "The Tax Compliance Game: Toward an Interactive Theory of Law Enforcement", Journal of Law, Economics and Organization, 2, 1-32.

[22] IRS (2006) "IRS Updates Tax Gap Estimates," IRS-2006-28.

[23] Khalil, F. (1997) "Auditing without commitment", RAND Journal of Economics, 28, 629-640.

[24] Khalil, F. and B. Parigi (1998) "Loan Size as a Commitment Device", International Economic Review, 39, 135-150.

[25] Kaplow, L. (1990) "Optimal Taxation with Costly Enforcement and Evasion", Journal of Public Economics, 43, 221-236.

[26] Kofman, F. and J. Lawarrée (1996) "On the optimality of allowing collusion", Journal of Public Economics, 61, 383-407.

[27] Kolm, S. (1973) "A Note on Optimum Tax Evasion", Journal of Public Economics, 2, 265-270.

[28] Landsberger, M., D. Monderer and I. Talmor (2000) "Feasible Net Income Distributions under Income Tax Evasion: an Equilibrium Analysis", Journal of Public Economic Theory, 2, 135-153.

[29] Liang, M.-Y. and C. C. Yang (2008) "How Much Should We Fund the IRS? An Exploration", Academia Sinica, mimeo.

[30] Marhuenda, F. and I. Ortuño-Ortín (1997) "Tax Enforcement Problems", Scandinavian Journal of Economics, 99, 61-72.

[31] Mayshar, J. (1991) "Taxation with Costly Administration", Scandinavian Journal of Economics, 93, 75-88.

[32] Melumad, N. and D. Mookherjee (1989) "Delegation as commitment: the case of income tax audits", RAND Journal of Economics, 20, 139-163.

[33] Mookherjee, D. (1997) "The Economics of Enforcement", in A. Bose, M. Rakshit and A. Sinha (eds.) Issues in Economic Theory and Policy, Essays in Honor of Tapas Majumdar, Oxford University Press, 202-249. 
[34] Mookherjee, D. and I. Png (1989) "Optimal Auditing, Insurance and Redistribution", The Quarterly Journal of Economics, 104, 399-415.

[35] Mookherjee, D. and I. Png (1990) "Enforcement Costs and the Optimal Progressivity of Income Taxes", Journal of Law, Economics, and Organizations, 6, 411-431.

[36] Pestieau, P., U. Possen and S. Slutsky (1994) "Optimal Differential Taxes and Penalties", Public Finance/Finances Publiques, 49, 15-27.

[37] Pestieau, P., U. Possen and S. Slutsky (1998) "The value of explicit randomization in the tax code", Journal of Public Economics, 67, 87-103.

[38] Pestieau, P., U. Possen and S. Slutsky (2004) "Jointly Optimal Taxes and Enforcement Policies in Response to Tax Evasion", Journal of Public Economic Theory, 6, 337-374.

[39] Picard, P. (1996) "Auditing claims in the insurance market with fraud: The credibility issue", Journal of Public Economics, 63, 27-56.

[40] Polinsky, M. and S. Shavell (2000) "The Economic Theory of Public Enforcement of Law", Journal of Economic Literature, 38, 45-76.

[41] Ray, D. and R. Vohra (2001) "Coalitional Power and Public Goods", Journal of Political Economy, 109, 1355-1384.

[42] Reinganum, J. and L. Wilde (1986) "Equilibrium Verification and Reporting Policies in a Model of Tax Compliance," International Economic Review, 27, 739-760.

[43] Sanchez, I. and J. Sobel (1993) "Hierachical design and enforcement of income tax policies", Journal of Public Economics, 50, 345-369.

[44] Sandmo, A. (1981) "Income Tax Evasion, Labour Supply and the Equity-Efficiency Trade-Off", Journal of Public Economics, 16, 265-288.

[45] Skinner, J. and J. Slemrod (1985) "An Economic Perspective on Tax Evasion", National Tax Journal, 38, 345-353.

[46] Slemrod, J. (1990) "Optimal Taxation and Optimal Tax Systems", Journal of Economic Perspectives, 4, 157-178.

[47] Slemrod, J. (1994) "Fixing the leak in Okun's bucket Optimal tax progressivity when avoidance can be controlled", Journal of Public Economics, 55, 41-51.

[48] Slemrod, J. and S. Yitzhaki (1987) "The Optimal Size of a Tax Collection Agency", Scandinavian Journal of Economics, 89, 183-192.

[49] Spicer, M. and S. Lundstedt (1976) "Understanding Tax Evasion", Public Finance/Finances Publiques, 31, 295-304.

[50] Usher, D. (1986) "Tax evasion and the marginal cost of public funds", Economic Inquiry, 24, 563-586. 